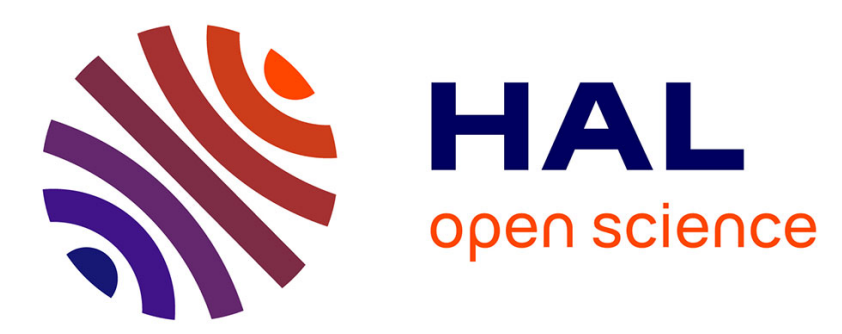

\title{
Deciphering Interfacial Reactions via Optical Sensing to Tune the Interphase Chemistry for Optimized Na-Ion Electrolyte Formulation
}

Parth Desai, Jiaqiang Huang, Hussein Hijazi, Leiting Zhang, Sathiya

Mariyappan, Jean- Marie Tarascon

\section{To cite this version:}

Parth Desai, Jiaqiang Huang, Hussein Hijazi, Leiting Zhang, Sathiya Mariyappan, et al.. Deciphering Interfacial Reactions via Optical Sensing to Tune the Interphase Chemistry for Optimized Na-Ion Electrolyte Formulation. Advanced Energy Materials, In press, pp.2101490. 10.1002/aenm.202101490 . hal-03318049

\section{HAL Id: hal-03318049 \\ https://hal.science/hal-03318049}

Submitted on 9 Aug 2021

HAL is a multi-disciplinary open access archive for the deposit and dissemination of scientific research documents, whether they are published or not. The documents may come from teaching and research institutions in France or abroad, or from public or private research centers.
L'archive ouverte pluridisciplinaire HAL, est destinée au dépôt et à la diffusion de documents scientifiques de niveau recherche, publiés ou non, émanant des établissements d'enseignement et de recherche français ou étrangers, des laboratoires publics ou privés. 
Deciphering interfacial reactions via optical sensing to tune the interphase chemistry for optimized Na-ion electrolyte formulation

Parth Desai, Jiaqiang Huang, Hussein Hijazi, Leiting Zhang, Sathiya Mariyappan, "and JeanMarie Tarascon*

P. D, Dr. J. H, Dr. H. H, Dr. S. M and Prof. J.-M. T

Chimie du Solide-Energie, UMR 8260, Collège de France, 75231 Paris Cedex 05, France

E-mail: sathiya.mariyappan@college-de-france.fr and jean-marie.tarascon@college-de-france.fr

P. D and Prof. J.-M. T

Sorbonne Université, 4 Place Jussieu, 75005, Paris, France

P. D, Dr. J. H, Dr. S. M and Prof. J.-M. T

Réseau sur le Stockage Electrochimique de l’Energie (RS2E), FR CNRS 3459, France

Dr. L. Z

Battery Electrodes and Cells, Electrochemistry Laboratory, Paul Scherrer Institute, Forschungsstrasse 111, 5232 Villigen-PSI, Switzerland

Keywords: Na-ion electrolytes, operando sensing, interphases, electrolyte additives, interfacial reactions

\begin{abstract}
Interphases, solid-electrolyte interphase (SEI) and cathode-electrolyte interphase (CEI) are the key influencers in determining battery life and performance. Especially, for technologies such as sodium ion batteries that are in development stage, it is crucial to tune the interphase chemistry without which it suffers at present from poor performance metrics for reaching real-life applications. In this study, we utilize optical sensors as a tool to follow operando, the thermal events of interfacial reactions and established the role of different electrolyte additives during the SEI/CEI formation. Using the acquired knowledge from sensing, together with complementary studies in Na-ion full-cells, we propose a new electrolyte formulation that showed stable cycling performance at $0-55{ }^{\circ} \mathrm{C}$ with very low self-discharge and improved safety due to mitigated
\end{abstract}


gassing during cycling. Finally, we nurture our studies by transferring the know-hows to prototype cylindrical 18650 cells. We hope such findings will accelerate the practical development of Na-ion batteries.

\section{Introduction}

Lithium ion batteries (LIBs), one of the most cherished electrochemical energy storage devices of today, are growing in demand as their usage spreads from electronic devices to electric vehicles as well as stationary applications ${ }^{[1]}$. However, limited lithium resources together with their uneven distribution in earth necessitate the development of additional complementary battery technologies to fulfil the need ${ }^{[2,3]}$. Sodium ion batteries (NIBs) that share similar chemistry as well as same production and engineering units with LIBs are expected to fill this gap and prototype NIBs have already been demonstrated by many start-up companies worldwide ${ }^{[4,5]}$. Still, NIBs lack an optimized electrolyte formulation to realize long cycle life, high safety and low self-discharge which are major requirements for reaching real-life applications ${ }^{[4,6]}$.

Back in 20 years, a humongous amount of work has been carried out to reach today's electrolyte formulation for Li-ion batteries. Nevertheless the challenges still persist for moving to high voltage positive electrodes (eg. lithium layered oxides, high voltage spinels etc) for increasing the energy density, where the redox process happens well beyond the electrolyte stability window ${ }^{[7]}$. In fact, Li-ion batteries are gifted with solid electrolyte interphase (SEI) that forms by the reduction of electrolyte solvents (eg. ethylene carbonate EC) on the negative electrode surface and protects it from further reaction with electrolyte. Similarly, but to a lesser extent there is the formation of a cathode-electrolyte interphase (CEI) at the positive electrode. The stability of the formed SEI/CEI determines the electrochemical performance of the cell, the reason why fine- 
tuning of SEI/CEI chemistry becomes essential ${ }^{[8]}$. Such a burden is not specific to Li-ion but common to all battery technologies. The still immature Na-ion battery is not an exception. The reasons are two-fold. First, the early reports show the insufficiency of organic carbonates in protecting the generally used hard carbon negative electrode and the poor stability of formed SEI upon repeated cycling due to higher solubility of the sodium-based SEI components than that of the Li-counterpart ${ }^{[9-11]}$. Second, alike Li-ion cathodes such as NMC and $\mathrm{LiMn}_{2} \mathrm{O}_{4}, \mathrm{Na}$-ion cathodes (sodium layered oxides or polyanionic $\mathrm{Na}_{3} \mathrm{~V}_{2}\left(\mathrm{PO}_{4}\right)_{2} \mathrm{~F}_{3}$ (NVPF)), need to be cycled to a similar upper cut-off voltage of $4.4 \mathrm{~V}$ and $4.3 \mathrm{~V}$ respectively to achieve the maximum capacity out of it. So at such high voltage, electrolyte degradation issues are problematic in both cases. In short, today's Na-ion chemistry suffers from electrolyte degradation at both positive (CEI) and negative (SEI) electrodes that hamper their long cycle life performances. Getting inspiration from the Li-ion technology, the most practical way to address this issue is the inclusion of additional substances, known as electrolyte additives ${ }^{[12]}$, to the main electrolyte for fine-tuning the SEI/CEI chemistry in Na-ion batteries.

The selection of appropriate electrolyte additive(s) requires robust knowledge on the reduction/ oxidation of the additive by itself, its reactivity with other electrolyte components (synergy), possible side reactions, cross-talk between the electrodes and also the nature of products formed. Hence, high throughput techniques are developed where thousands of electrolyte formulations differing by the nature of their components and compositions can be tested to select the best one ${ }^{[13]}$. In parallel, research efforts have also been directed towards the design of special cells to follow interfacial reactions operando condition using techniques such as X-ray photoelectron spectroscopy $^{[14]}$ (XPS), nuclear magnetic resonance ${ }^{[15,16]}$ (NMR), transmission electron microscopy ${ }^{[17]}$ (TEM) etc. Along that line, our group has recently demonstrated the use of optical 
sensors that can be placed inside cylindrical/pouch cells as an elegant tool to follow operando the heat associated to the chemical reactions during the formation and cycling of the cells ${ }^{[18]}$. The facile integration of optical sensors with cylindrical/pouch cells helps in exactly mimicking the real-life conditions, hence providing more reliable results.

In the present study, we extend the optical sensing approach to follow indirectly, via heat release, the chemical reactions happening at the electrode-electrolyte interface and the reactivity of electrolyte additives. By combining the knowledge gained from heat generated by different interfacial reactions with parallel electrochemical analyses on NVPF/hard carbon (HC) full cells and NVPF/NVPF, HC/HC symmetric cells, we succeed in grasping the role of different electrolyte additives and their synergy. Based on these observations, we propose an electrolyte formulation having $1 \mathrm{M} \mathrm{NaPF} 6$ in organic carbonates (ethylene carbonate $\mathrm{EC} /$ propylene carbonate PC/ dimethyl carbonate DMC) as the mother electrolyte with 4 additives namely sodium oxalato(difluoro)borate ${ }^{[19]}(\mathrm{NaODFB})$, vinylene carbonate ${ }^{[20]}(\mathrm{VC})$, $_{\text {succinonitrile }}^{[21]}(\mathrm{SN})$ and tris-trimethylsilylphosphite ${ }^{[22]}$ (TMSPi). It shows an optimum electrochemical performance at different cycling temperatures $\left(0,25\right.$ and $\left.55^{\circ} \mathrm{C}\right)$ while having minimum self-discharge. Moreover, we prove the feasibility of transferring the electrolyte to cylindrical 18650 cells, based on the NVPF/HC chemistry that exhibited stable cycling performance at $55^{\circ} \mathrm{C}$, with less gassing.

\section{Results and discussions}

\subsection{Selection of mother/ control electrolyte and the heat evolution during formation cycle}

As the starting point, the mother electrolyte has to be properly defined. From some of our previous studies and surveys ${ }^{[23-25]}$, our choice in terms of chemical/electrochemical reactivity and overall performances, narrowed down to $1 \mathrm{M} \mathrm{NaPF}_{6}$ dissolved in mixture of ethylene carbonate (EC) - propylene carbonate (PC) - dimethyl carbonate (DMC), with a volume ratio of 1: 1: 1 
respectively. EC was chosen because of its key role in the SEI formation ${ }^{[26]}$, DMC the linear carbonate usually incorporated in the electrolyte to reduce its viscosity hence increase the conductivity/wettability ${ }^{[27]}$. Finally, PC was utilized since it plays an important role in decreasing the freezing point of the electrolyte thus being important for low temperature applications ${ }^{[27-29]}$. Prior to their use, all the solvents were dried by molecular sieves and tested for their water content by Karl Fischer titration which was less than 5 ppm after drying process. The electrolyte produced by dissolving $1 \mathrm{M} \mathrm{NaPF}_{6}$ in a mixture of EC- PC- DMC (1: $1: 1$ by volume) exhibit ionic conductivity of $6.07,11.14$ and $15.9 \mathrm{mS} \mathrm{cm}^{-1}$ at 0,25 and $55^{\circ} \mathrm{C}$, respectively. The cycling performance of the electrolyte was then analyzed using coin cells composed of $\mathrm{Na}_{3} \mathrm{~V}_{2}\left(\mathrm{PO}_{4}\right)_{2} \mathrm{~F}_{3}$ (NVPF) and hard carbon (HC) as positive and negative electrode respectively. The electrode materials (NVPF and HC) used throughout this manuscript are derived from same batches of positive and negative electrode active materials that were coated and calendared in the same way in order to have reliable and meaningful comparisons. The tests were carried out at $55^{\circ} \mathrm{C}$ in order for accelerated testing ${ }^{[30]}$. The cells using the electrolyte formulation $1 \mathrm{M} \mathrm{NaPF}_{6}$ in a mixture of EC- PC- DMC exhibited good cycling performance (see Figure S1 in the Supporting Information) and used as mother electrolyte for the rest of this study. The additive-free mother electrolyte is hereafter referred as 'control', in order to differentiate it from the additivecontaining electrolyte formulations which are named according to the identity of the involved additives.

The chemical/electrochemical stability of the control electrolyte was tested for its heat evolution during the SEI formation in 18650 NVPF/ HC cells using our recently developed calorimetry technique based on optical sensors ${ }^{[18]}$. For this purpose, we received electrolyte-free and sealed NVPF/ HC 18650 cells from TIAMAT (France), hence providing freedom to add 
multitude of electrolyte combinations while maintaining all the other assembling parameters constants. The cells were pierced to one end with the hole that was used to fill the cell with our electrolyte of choice and also to inject the optical fiber Bragg grating (FBG) sensor prior to be sealed by epoxy. Two other FBG sensors were placed at the cell surface and in its surrounding ambient to perform reliable calorimetry measurements. The cells together with the FBGs were placed in an oven at fixed temperature of $55{ }^{\circ} \mathrm{C}$ and formatted following a protocol that consisted of cycling the cell at $\mathrm{C} / 10$ rate for 3 charge- discharge cycles. The current and potential of the cells were measured by Bio-Logic potentiostat/ galvanostat and the charge curves for three cycles are shown in Figure 1a for the control electrolyte. The FBGs were connected with the optical interrogator to analyze the shift in Bragg wavelength $\left(\Delta \lambda_{B}\right)$ that was converted to temperature variations $(\Delta T)$ with high resolutions $\left(1 \mathrm{~s}\right.$ and $\left.0.1{ }^{\circ} \mathrm{C}\right)$ as shown in Figure $1 \mathrm{~b}$. The $\Delta T$ in turn was used to calculate the heat ( $\dot{Q}$ in Figure 1c) using a simplified zero-dimensional thermal model whose intrinsic parameters must be defined for each cells prior conducting the measurements (Figure S2, Supporting Information). The heat derivative as a function of voltage was calculated $\left(\mathrm{d} Q_{\text {heat }} / \mathrm{d} V\right.$ in Figure $\left.1 \mathrm{~d}\right)$ and compared with the capacity derivative $\mathrm{dQ}_{\mathrm{cap}} / \mathrm{dV}$ in Figure $1 \mathrm{e}$. From Figure $1 \mathrm{~d}$ and e, it can be seen that, while very less change in shape is observed in capacity derivative $\left(\mathrm{d} Q_{\text {cap }} / \mathrm{d} V\right)$ among the first three charges, a huge change is observed in heat derivatives $\left(\mathrm{d} Q_{\text {heat }} / \mathrm{d} V\right.$ ) where the heat evolution is maximum for the first charge and reduced drastically for the second and third ones. These findings demonstrate the viability of using heat evolution, as determined by FBGs, as a tool to follow the interfacial reactions between electrodes and electrolyte within NPVF/HC cells.

The observed heat changes can be associated with either electrolyte parasitic redox reactions or with electrode material where the phase transitions and diffusion limited kinetics can play a 
role ${ }^{[18]}$. However, since the contributions from electrode materials are expected to be similar on subsequent cycles, the irreversible heat evolutions observed in the first charge are mainly correlated with the electrolyte redox process.

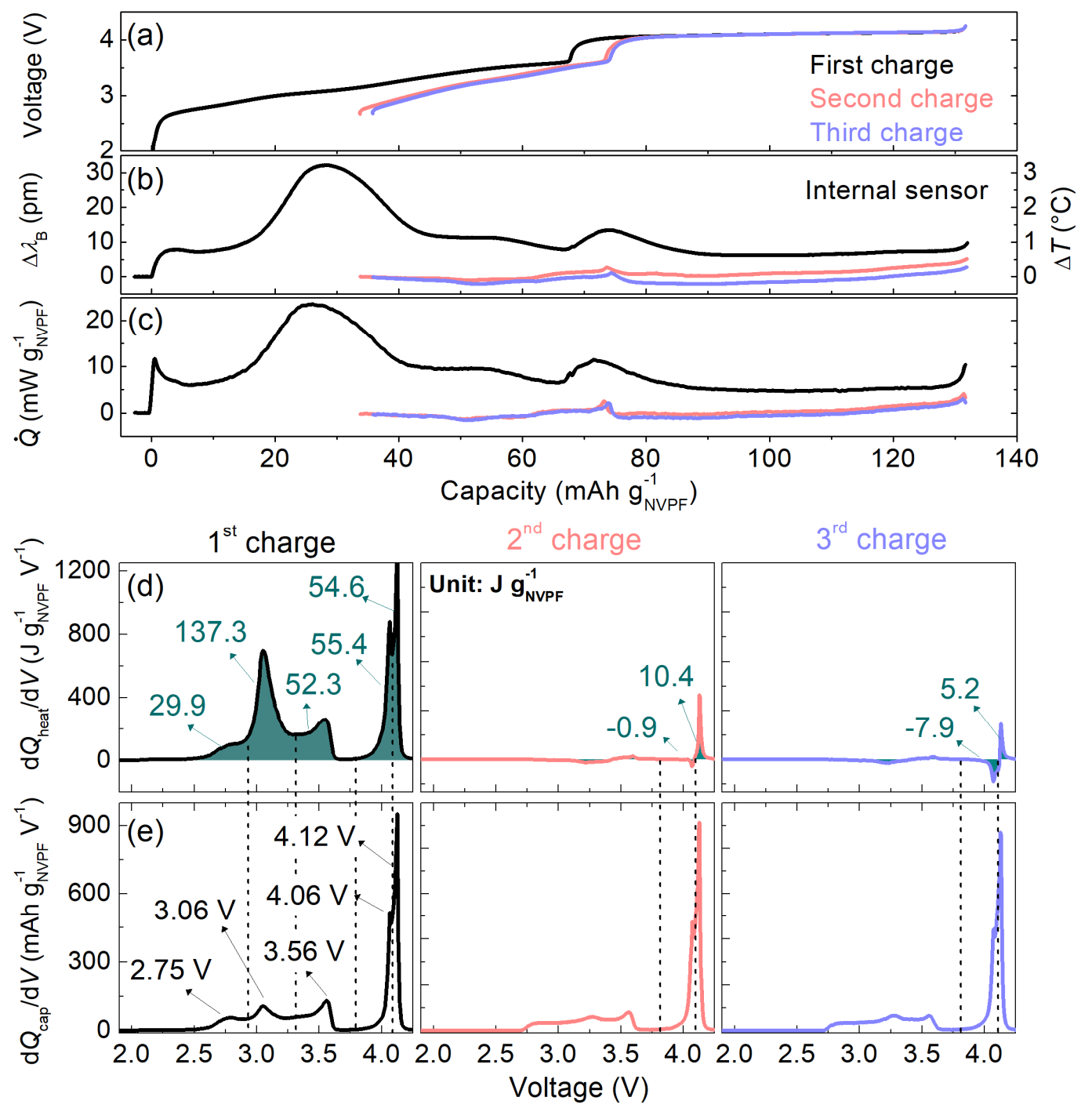

Figure 1. The sensing studies on NVPF/ HC cells using control electrolyte. (a) The capacity vs voltage plot (b) The change in Bragg wavelength $\left(\Delta \lambda_{B}\right)$ measured by FBGs and converted to the equivalent temperature change $(\Delta \mathrm{T})$ in the right $\mathrm{y}$-axis as a function of capacity. (c) The heat $\dot{Q}$ as a function of capacity. (d) Derivative of heat evolution $\left(\mathrm{d} Q_{\text {heat }} / \mathrm{d} V\right)$, mentioned values indicate integrated heat in $\mathrm{J} / \mathrm{g}_{\mathrm{NVPF}}$ for regions separated by dashed line and (e) Derivative of capacity $\left(\mathrm{d} Q_{\text {cap }} / \mathrm{d} V\right)$ as a function of cell voltage for the $1^{\text {st }}, 2^{\text {nd }}$, and $3^{\text {rd }}$ charges, voltage values corresponding to the peaks are labelled in the 
figure. The experiment was duplicated using two cells with exact configuration and identical results were observed in both cells. The cells were cycled at $55^{\circ} \mathrm{C}$ from 2 to $4.25 \mathrm{~V}$ at $\mathrm{C} / 10$ rate $\left(1 \mathrm{C}=128 \mathrm{mAh} \mathrm{g}{ }^{-1}\right)$.

By comparing the potential of the NVPF and HC individual electrodes (see Figure S3 in the Supporting Information), the region from OCV to $3.8 \mathrm{~V}$ corresponds to the slopy region of hard carbon, hence the observed exothermic peaks at 2.75, 3.06 and $3.56 \mathrm{~V}$ (Figure 1e) are correlated with the SEI formation which stabilized after the first cycle. In contrast, the other two exothermic peaks (4.06 and $4.12 \mathrm{~V}$ ) occurring beyond $50 \%$ of the cell charging capacity happens in the high voltage plateau of NVPF hence includes heat of reaction related to $\mathrm{Na}_{2} \mathrm{~V}_{2}\left(\mathrm{PO}_{4}\right)_{2} \mathrm{~F}_{3}-$ $\mathrm{NaV}_{2}\left(\mathrm{PO}_{4}\right)_{2} \mathrm{~F}_{3}$ phase transition as well as diffusion limited kinetics, in addition to the possible electrolyte oxidation. The process at $4.06 \mathrm{~V}$ becomes endothermic on $2^{\text {nd }}$ and $3^{\text {rd }}$ charges indicating the exothermic heat observed in $1^{\text {st }}$ charge is mainly from electrolyte oxidation. However, only a decrease in exothermicity is observed for the process at $4.12 \mathrm{~V}$ in moving from $1^{\text {st }}$ to $2^{\text {nd }}$ and $3^{\text {rd }}$ charges, hence it is correlated with electrolyte oxidation as well the diffusion limited kinetics at the end of charge from material ${ }^{[18]}$.

\subsection{Understanding the role of electrolyte additives by sensing}

Next, we studied how the heat events occurring through the charging process are evolving upon the addition of various chemical additives. For this purpose, the additives selected from sodium oxalato(difluoro)borate (NaODFB), vinylene carbonate $(\mathrm{VC})$, succinonitrile $(\mathrm{SN})$ and tristrimethylsilylphophite (TMSPi) were added to the mother electrolyte, consecutively in a defined ratio, starting from $0.5 \mathrm{wt} \% \mathrm{NaODFB}, 3 \mathrm{wt} \% \mathrm{VC}, 3 \mathrm{wt} \% \mathrm{SN}$ and $0.2 \mathrm{wt} \%$ TMSPi. All these additives were selected as they are widely in-use for LIBs and also understudy for NIBs as

reported earlier ${ }^{[19,24,25]}$. For each electrolyte formulation, the measurements were done at least 
twice to ensure the reproducibility of the results. In total, 5 different electrolyte formulations namely control, $\mathrm{NaODFB}, \mathrm{NaODFB}+\mathrm{VC}, \mathrm{NaODFB}+\mathrm{VC}+\mathrm{SN}$ and $\mathrm{NaODFB}+\mathrm{VC}+\mathrm{SN}+\mathrm{TMSPi}$ were studied and the cycling curves with their corresponding $\mathrm{d} Q_{\text {cap }} / \mathrm{d} V$ plots are shown in Figures S4 and S5 in the Supporting Information.

The $\Delta T$ measured from FBG's is used to derive the $\mathrm{dQ}_{\text {heat }} / \mathrm{dV}$ derivative plots as explained for the control and the data for $1^{\text {st }}$ charge are shown in Figure 2 (a-e) with that of $2^{\text {nd }}$ and $3^{\text {rd }}$ charges in Figure S6 of Supporting Information. For the sake of clarity, we plotted the data in two panels that reunite the heat events occurring below $3.8 \mathrm{~V}$ (left) and those above (right) to decouple the impacts of the additive on the HC and NVPF electrodes respectively. Note that the onset potential of the new thermal events compared to the control electrolyte together with their amplitudes is a function of the additive used. The total evolved heat in both of these voltage regions $(<3.8 \mathrm{~V}$ and $>3.8 \mathrm{~V}$ ) for each electrolyte formulation is plotted in Figure $2 \mathrm{f}$ (bottom panel). Strikingly, there is an abrupt decrease in the cumulated heat in the two voltage regions with the addition of electrolyte additive(s) (Figure 2f) implying the additives assist the formation of SEI and CEI that reduce the unwanted parasitic reactions with the electrolyte solvents.

Nearly $50 \%$ reduction in evolved heat is observed just by the addition of the single additive NaODFB (Figure 2b) demonstrating the reactivity of NaODFB or its derived product in both negative and positive electrodes. The heat due to NaODFB reduction at $\sim 2 \mathrm{~V}$ is much less, around $2 \mathrm{~J} / \mathrm{g}_{\mathrm{NVPF}}$, implying its effectiveness in protecting the electrode surface without actually releasing unwanted heat. Still, the peaks owing to solvent reduction at $2.75,3.06$ and $3.56 \mathrm{~V}$ persist suggesting that solely NaODFB is not sufficient in stopping excessive solvent reduction. When VC was added together with NaODFB (Figure 2c), a nearly complete reduction in heat associated with solvent reduction at $3 \mathrm{~V}$ is observed. The heat profile consists of 2 new 
exothermic processes at $2.6 \mathrm{~V}$ and $2.8 \mathrm{~V}$, where the $2.8 \mathrm{~V}$ process overlaps with the solvent reduction observed in the control electrolyte $(2.75 \mathrm{~V})$. The peak at $2.6 \mathrm{~V}$ corresponds to $1.0 \mathrm{~V}$ in

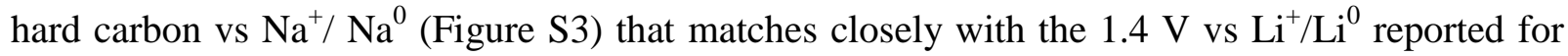
vinylene carbonate reduction ${ }^{[31]}$. Further, a closer comparison using $\mathrm{dQ}_{\mathrm{cap}} / \mathrm{dV}$ with $\mathrm{dQ}_{\text {heat }} / \mathrm{dV}$ plot (Figure S7, Supporting Information) showed that both 2.6 and $2.8 \mathrm{~V}$ redox process exhibit nearly similar heat evolution (21 and $19 \mathrm{~J}$ per gram of NVPF), however solely 0.065 electron $\left(0.065 \mathrm{Na}^{+}\right.$ removal from NVPF) is involved at $2.6 \mathrm{~V}$ reduction versus 0.22 electron at $2.8 \mathrm{~V}$ reduction. The result indicates the $\mathrm{VC}$ reduction at $2.6 \mathrm{~V}$ is either highly exothermic or associated with parallel chemical reaction that evolves huge amount of heat. It correlates well with the VC redox mechanism reported in literature where $\mathrm{VC}$ involves a 1 or 2 electron redox process ${ }^{[32-34]}$ (exothermic peak at $2.6 \mathrm{~V}$ ) with the products of $\mathrm{VC}$ reduction that in turn reacts with $\mathrm{EC}$ (peak at $2.8 \mathrm{~V}$ ) and polymerize with the release of $\mathrm{CO}_{2}$. The evolved heat at $2.6 \mathrm{~V}$ is relatively higher when VC is used alone (see Figure S8 in the Supporting Information) without NaODFB as the available $\mathrm{HC}$ surface is higher without passivation by NaODFB. In the high voltage region (3.84.25 V), the addition of $\mathrm{VC}$ reduced the overall heat and relatively less changes in heat of reaction are observed in the second and third charges (see Figure S6 in the Supporting Information ) indicating possible passivation and stabilization of positive electrode as well.

The additive succinonitrile (SN) was tested next as it was reported to be efficient in protecting the positive electrode ${ }^{[21,35-37]}$. The addition of $\mathrm{SN}$ to $\mathrm{NaODFB}+\mathrm{VC}$ further reduced the heat associated with high-voltage region $(>3.8 \mathrm{~V})$ process indicating a relatively less severe electrolyte oxidation in the positive electrode, hence suggesting a synergetic effect ${ }^{[37]}$ of SN together with VC to protect the positive electrode efficiently (Figure 2d). However, we do not see 
any new specific feature pertaining to the addition of $\mathrm{SN}$ that could suggest its oxidation or adsorption on electrode surface.

\section{(a) Control}

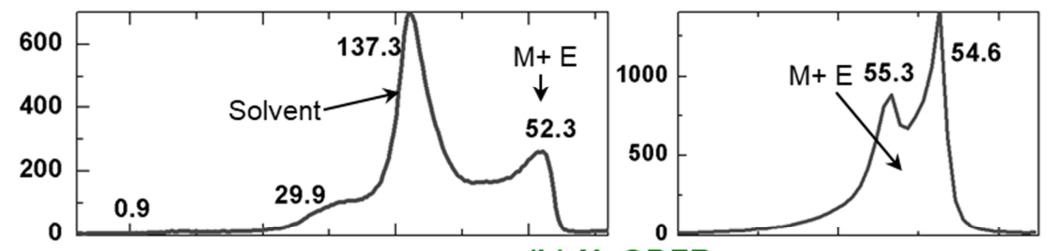

(b) NaODFB

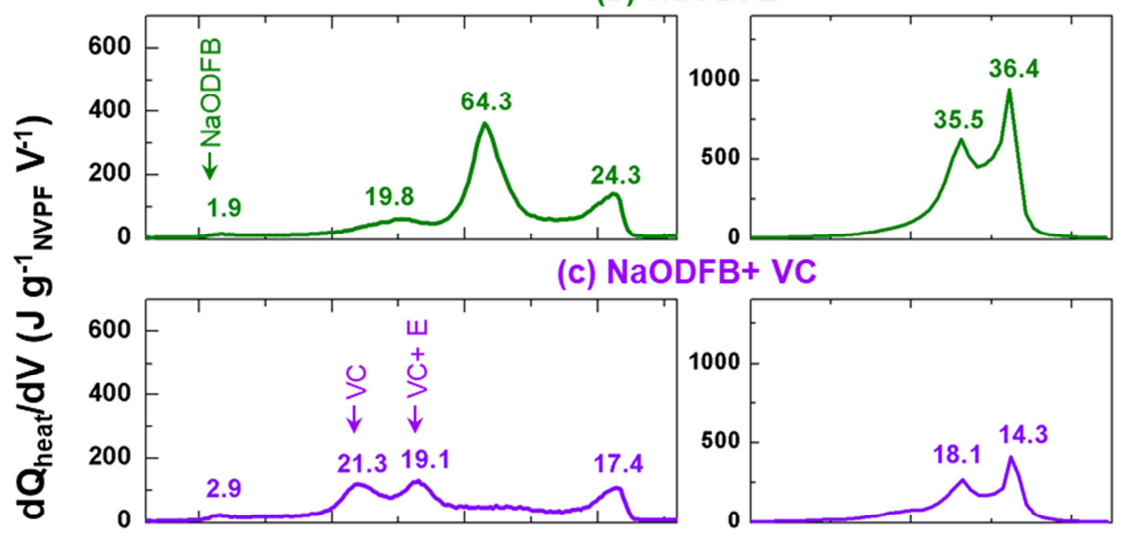

(d) NaODFB+ VC+ SN

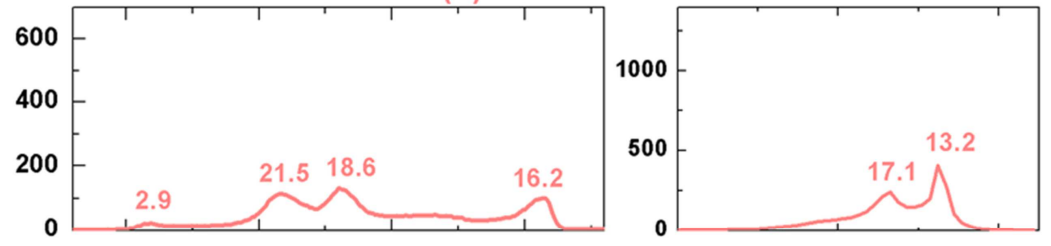

(e) NaODFB+ VC+ SN+ TMSPi
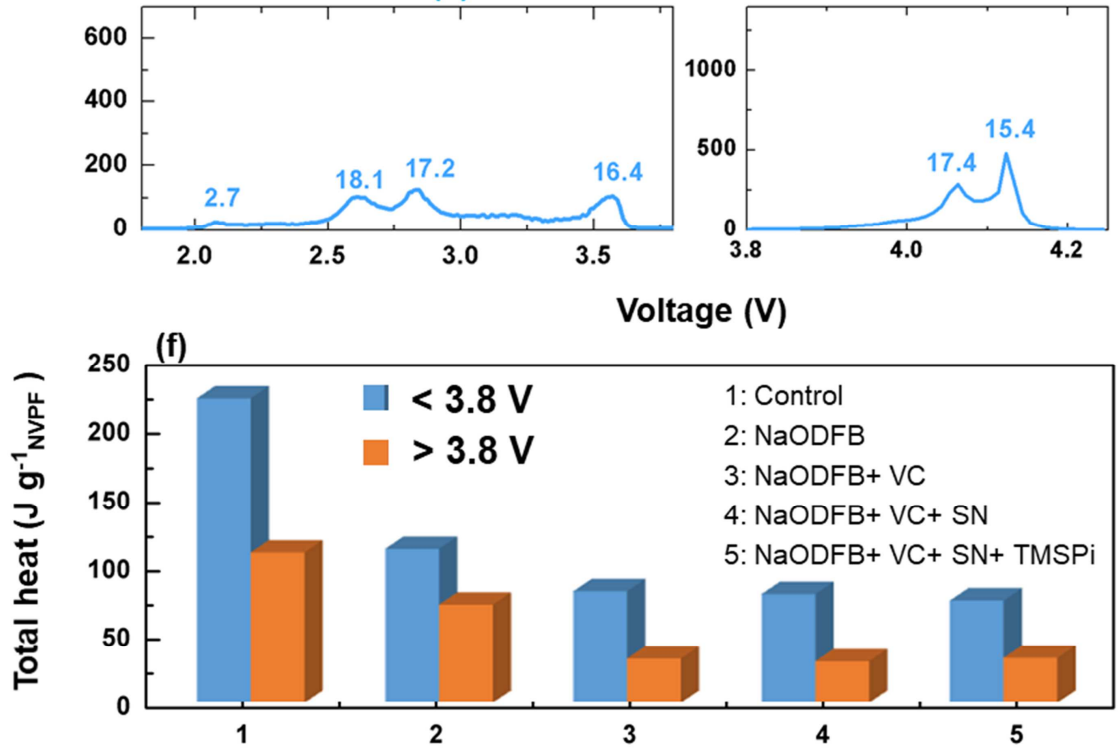
Figure 2. (a-e) The derivatives of heat with respect to voltage $\left(\mathrm{d} Q_{\text {heat }} / \mathrm{d} V\right)$ of NVPF/HC cylindrical 18650 cells cycled at $\mathrm{C} / 10$ in an oven maintained at $55^{\circ} \mathrm{C}$, using $1 \mathrm{M} \mathrm{NaPF}_{6}$ in 1: 1: 1 (by volume) of EC: PC: DMC electrolyte with (a) no additives- control, and with the additives (b) $0.5 \mathrm{wt} \% \mathrm{NaODFB}$, (c) $0.5 \mathrm{wt} \%$ $\mathrm{NaODFB}+3 \mathrm{wt} \% \mathrm{VC}$, (d) $0.5 \mathrm{wt} \% \mathrm{NaODFB}+3 \mathrm{wt} \% \mathrm{VC}+3 \mathrm{wt} \% \mathrm{SN}$, and (e) $0.5 \mathrm{wt} \% \mathrm{NaODFB}+3 \mathrm{wt} \%$ $\mathrm{VC}+3 \mathrm{wt} \% \mathrm{SN}+0.2 \mathrm{wt} \%$ TMSPi. The figures in the left show the voltage window from OCV-3.8 $\mathrm{V}$ and the right ones show the voltage window from 3.8 to $4.25 \mathrm{~V}$. The integrated heats (in joule per gram of NVPF) of SEI/CEI formation peaks were labelled and the arrow marks are guide to eyes to show the redox process of $\mathrm{NaODFB}, \mathrm{VC}$, electrolyte solvent (E) and heat evolution due to sodium (de-)insertion in the material (M). (f) The total heat observed at $<3.8 \mathrm{~V}$ and $>3.8 \mathrm{~V}$ as a function of electrolyte formulation.

Similarly, addition of TMSPi $(0.2 \mathrm{wt} \%)$ also did not show any new feature in the heat derivative plot, with the exception of a reduction of the evolved heat in the low voltage processes $(<3.8 \mathrm{~V}$; Figure 2e). It is known from literature that TMSPi is an effective acid $/ \mathrm{O}_{2}$ scavenger $^{[22,38,39]}$ and this could be responsible for the reduced heat in the low voltage process. On the contrary, a slight increase in heat is observed at high voltages that we are associating to the oxidation of TMSPi

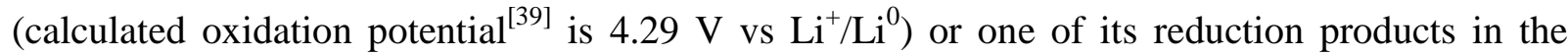
positive electrode.

Altogether, these calorimetry measurements indicated a reactivity of the studied electrolyte additives both at the NVPF and HC electrodes with the exception of SN that solely showed an activity on the NVPF electrode. Moreover, the additive mixture of NaODFB with VC participate in the formation of both SEI and CEI, whereas SN, TMSPi may be helpful to fine-tune them further as they exhibited further reduction in heat of reaction since the smallest heat was obtained when the four additives altogether were added to our mother electrolyte. Such a finding provided a very useful guidance but not sufficient in deriving the best suitable electrolyte for the NVPF/HC chemistry. Hence, we substantiated our studies by electrochemical analyses using the same combinations of additive blends in NVPF/HC Na-ion full cells. 


\subsection{Electrochemical analyses in Na-ion full cells:}

Coin-type 2032 cells were assembled and cycled at $55^{\circ} \mathrm{C}$ between $2-4.3 \mathrm{~V}$ according to the following experimental protocol. For data robustness, a minimum of 2 coin cells were assembled with each electrolyte formulations and the cells were initially cycled at C/5 rate for 10 times to form the stable SEI/ CEI prior applying a self-discharge test by keeping the cells at rest on $100 \%$ state of charge $(4.3 \mathrm{~V})$ for 1 week at $55^{\circ} \mathrm{C}$. After the self-discharge test, the cycling was resumed and the capacity recovered after the self-discharge period $\left(\mathrm{Q}_{\mathrm{n}}\right)$ was used to calculate the loss due to self-discharge $\left(\mathrm{Q}_{\mathrm{n}-1}-\mathrm{Q}_{\mathrm{n}}\right)$. The capacity of the subsequent cycle $\left(\mathrm{Q}_{\mathrm{n}+1}\right)$ is the recovered capacity. For clarity, the cycling curves for $n-1, n$ and $n+1^{\text {th }}$ cycles alone for all electrolyte formulations are shown in Figure 3(a-d) with the complete cycling data in Figure S9 of the Supporting Information. The addition of electrolyte additives improves the stability during self-discharge test, and all the electrolytes with additives showed only a 9-10\% of capacity loss during 1 week rest at $55{ }^{\circ} \mathrm{C}$, while the control electrolyte exhibits $16 \%$ loss with solely $90 \%$ recovery (Figure $3 e)$.

An increase in polarization is observed with all electrolyte formulations after the self-discharge test. The polarization is calculated as the difference in average cell voltage between charge and discharge and mentioned in figure 3a-d. The electrolytes with NaODFB+ VC and NaODFB+ $\mathrm{VC}+\mathrm{SN}+\mathrm{TMSPi}$ showed the least change in polarization $\left(\Delta \mathrm{V}_{\mathrm{n}+1^{-}}-\Delta \mathrm{V}_{\mathrm{n}-1}=\sim 20 \mathrm{mV}\right)$ in line with the best capacity recovery of 94.7 and $96.6 \%$ respectively. A relatively higher increase in polarization $(\sim 50 \mathrm{mV})$ is observed with $\mathrm{NaODFB}+\mathrm{VC}+\mathrm{SN}$ and the highest with control electrolyte $(\sim 100 \mathrm{mV})$. The results show possible SEI/ CEI growth due to side reactions during rest hence increased impedance. 


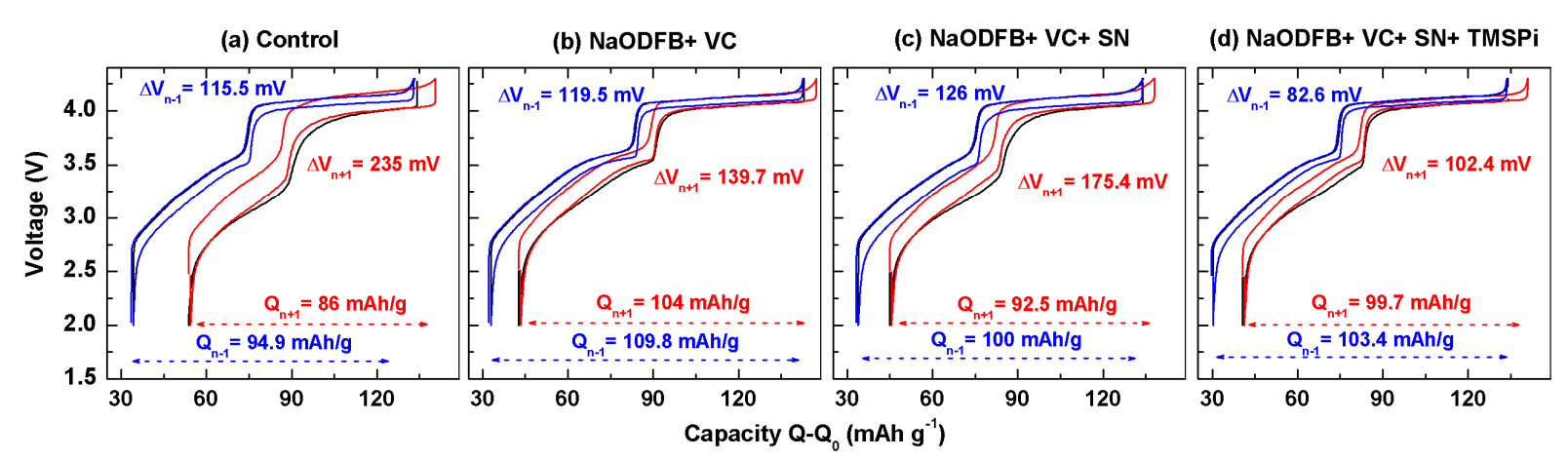

(e) Self discharge loss and recovery

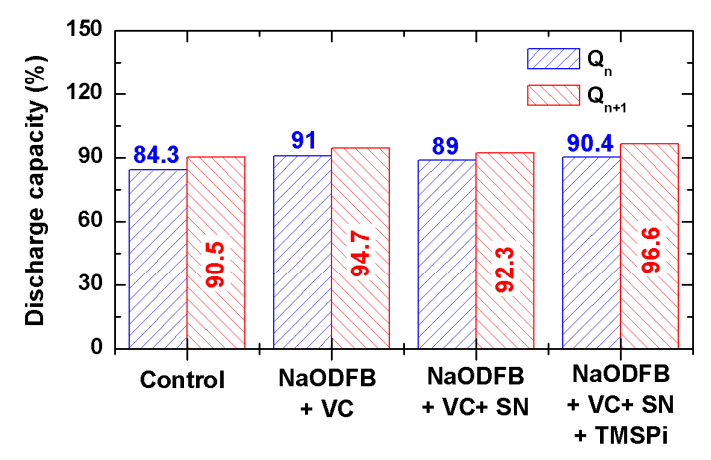

(f) Capacity retention

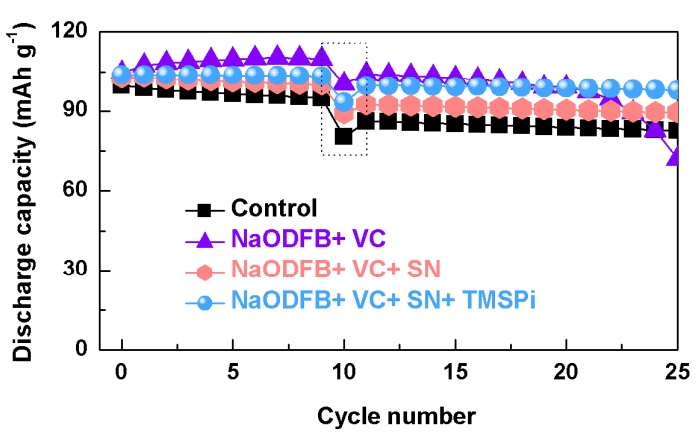

Figure 3. a-d) Cycling curves of NVPF/HC cells (derived from Figure S9 of the Supporting Information) using 4 different electrolyte formulations, where only the cycle corresponds to self-discharge test and the recovery cycle are shown. $\mathrm{Q}_{\mathrm{n}}$ and $\mathrm{Q}_{\mathrm{n}+1}$ represent the capacity after self-discharge and the recovered capacity in subsequent cycle. (e) discharge capacity during self-discharge and recovery cycle and (f) Capacity retention of the cells using control electrolyte, and with the additives $0.5 \mathrm{wt} \% \mathrm{NaODFB}, 0.5$ wt $\%$ NaODFB+ 3 wt $\%$ VC, $0.5 \mathrm{wt} \%$ NaODFB+ 3 wt $\%$ VC+ 3 wt $\%$ SN, and $0.5 \mathrm{wt} \%$ NaODFB+ $3 \mathrm{wt} \%$ $\mathrm{VC}+3 \mathrm{wt} \% \mathrm{SN}+0.2 \mathrm{wt} \%$ TMSPi.

The capacity retentions of all the cells before and after the self-discharge test are shown in Figure 3e. A stable capacity retention with slightly reduced capacity after self-discharge is observed with all electrolyte formulations except $\mathrm{NaODFB}+\mathrm{VC}$ that showed initial increase in capacity and sudden drop after 15-20 cycles. Notably, the NaODFB+ VC exhibit less self-discharge loss ( 9 $\%$ ) and only $\sim 20 \mathrm{mV}$ increase in polarization after self-discharge tests. In this case, the observed deterioration is unexpected and we tried to understand it further via a dV/dQ analyses ${ }^{[40,41]}$ of the full cells. It can be expressed as $d V_{\text {cell }} / d Q=\left(d V_{\text {cathode }} / d Q\right)-\left(\mathrm{dV}_{\text {anode }} / \mathrm{dQ}\right)$, hence enabling the feasibility to distinguish the degradation contribution from positive and negative electrodes separately without inserting a reference electrode. 
In the previous work ${ }^{[42]}$ from our group, we have shown that such analysis becomes extremely simple for the NVPF/HC system which shows a single and well defined peak between the two plateaus $\left(\mathrm{Na}_{3} \mathrm{~V}_{2}\left(\mathrm{PO}_{4}\right)_{2} \mathrm{~F}_{3} \rightarrow \mathrm{Na}_{2} \mathrm{~V}_{2}\left(\mathrm{PO}_{4}\right)_{2} \mathrm{~F}_{3}\right.$ and $\left.\mathrm{Na}_{2} \mathrm{~V}_{2}\left(\mathrm{PO}_{4}\right)_{2} \mathrm{~F}_{3} \rightarrow \mathrm{Na}_{1} \mathrm{~V}_{2}\left(\mathrm{PO}_{4}\right)_{2} \mathrm{~F}_{3}\right)$ with the derivative shooting to infinite at the very beginning and at the end of charge-discharge, respectively. Briefly, the shift of the peak (NVPF slippage) and the shoot (HC slippage) shown in Figure $4 \mathrm{a}$ are indicative of the NVPF and HC degradation, respectively. Figure 4 shows the variations of the $\mathrm{dV}_{\text {cell }} / \mathrm{dQ}$ analysis for the $1^{\text {st }}, 10^{\text {th }}$ and $20^{\text {th }}$ discharge cycles for the control electrolyte and the derived ones containing different additives. From these $\mathrm{dV}_{\text {cell }} / \mathrm{dQ}$ plots we directly visualized the beneficial effects of the four additives with barely any change at the positive electrode. For better comparison, we plotted the variation of the NVPF and HC slippages for various electrolytes in Figure $4 \mathrm{~b}$ and the least slippage of both electrodes is obtained for the four additive components electrolytes.

However, worth mentioning is the case of $\mathrm{VC}+\mathrm{NaODFB}$ which initially showed a shift of the NVPF and HC to opposite (negative) directions than for the other electrolytes prior to follow the similar trend after the $10^{\text {th }}$ cycle. It means that, in this case we have the oxidation of the electrolyte with simultaneous insertion of $\mathrm{Na}^{+}$in the $\mathrm{HC}$, leading to higher capacity hence negative slippage on both NVPF and HC. 

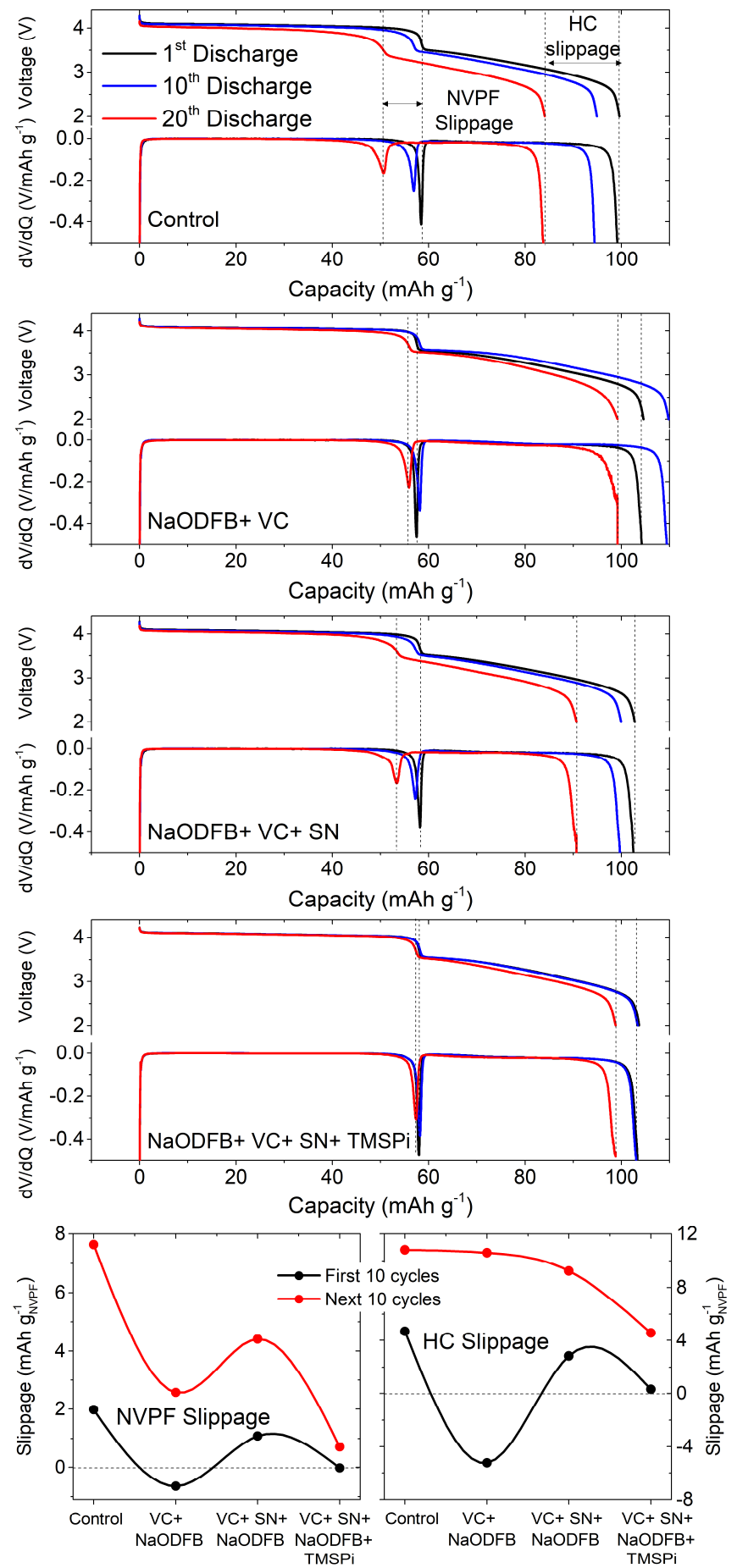

Figure 4. (a) The discharge voltage versus capacity plots of the $1^{\text {st }}, 10^{\text {th }}$ and $20^{\text {th }}$ cycles together with differential voltage $(\mathrm{dV} / \mathrm{dQ})$ for the cells with control electrolyte, and with the additives $0.5 \mathrm{wt} \%$ NaODFB, 0.5 wt $\%$ NaODFB+ 3 wt $\%$ VC, 0.5 wt $\%$ NaODFB+ 3 wt $\%$ VC+ 3 wt $\%$ SN, and $0.5 \mathrm{wt} \%$ $\mathrm{NaODFB}+3 \mathrm{wt} \% \mathrm{VC}+3 \mathrm{wt} \% \mathrm{SN}+0.2 \mathrm{wt} \% \mathrm{TMSP}$. The curves are derived from NVPF/HC cells for which the original data is shown in Figure S9 of the Supporting Information. (b) The capacity slippage in positive (NVPF) and negative (HC) electrodes calculated from (a). 
The poor oxidative stability of $\mathrm{NaODFB}+\mathrm{VC}$ is re-confirmed from more pronounced end-point slippage in charge than in discharge (see Figure S10 in the Supporting Information). Charge endpoint slippage and Discharge endpoint slippage values gives indication about electrolyte oxidation and $\mathrm{Na}^{+}$inventory loss for the SEI growth, respectively ${ }^{[43,44]}$. Yet, it must be realized that all these analyses in NVPF/HC full cells include cross-talk (e.g., shuttle) between oxidation and reduction parasitic species formed at the positive and negative electrode, respectively. Therefore separating this cross-talk and identifying the electrolyte stability against a single mode of degradation becomes essential.

To interrogate the cross-talking between electrodes, we followed Jeff Dahn's approach of symmetric cells cycling ${ }^{[45-47]}$. Cells using desodiated $\mathrm{Na}_{1} \mathrm{~V}_{2}\left(\mathrm{PO}_{4}\right)_{2} \mathrm{~F}_{3} \mid$ sodiated $\mathrm{Na}_{3} \mathrm{~V}_{2}\left(\mathrm{PO}_{4}\right)_{2} \mathrm{~F}_{3}$ and desodiated hard carbon | sodiated hard carbon, respectively were assembled with electrodes prepared and recovered according to the protocol described in experimental section. The representative cycling curves and individual electrode curves calculated with dV/dQ fitting software $^{[41]}$ are presented in Figure S11 and Note S1 of the Supporting Information. The changes in the cycling curves are associated with the degradation mode and shown in Figure S12 and Note S2-S3 of the Supporting Information. It is worth noting that dominant mechanism for degradation of NVPF and HC symmetric cell is electrolyte oxidation and electrolyte reduction, respectively. The cumulated capacity retention plots of both NVPF and HC symmetric cells are shown in Figure 5.

For NVPF symmetric cells, the least capacity retention is observed for the control and $\mathrm{VC}+\mathrm{NaODFB}$ additive combination (Figure 5a) and the capacity decay is well pronounced starting from initial cycles. This implies that the observed deterioration in full cells (Figure 3f) mainly comes from poor oxidative stability of electrolyte as deduced earlier from the slippage calculations. However, the electrolyte stability improved drastically by the addition of SN that 
protects the NVPF electrode and improves the oxidative stability of the electrolyte. Addition of TMSPi to NaODFB+ VC+ SN did not bring any significant change in the stability, while similar performance to that of $\mathrm{NaODFB}+\mathrm{VC}+\mathrm{SN}$ without TMSPi is observed.
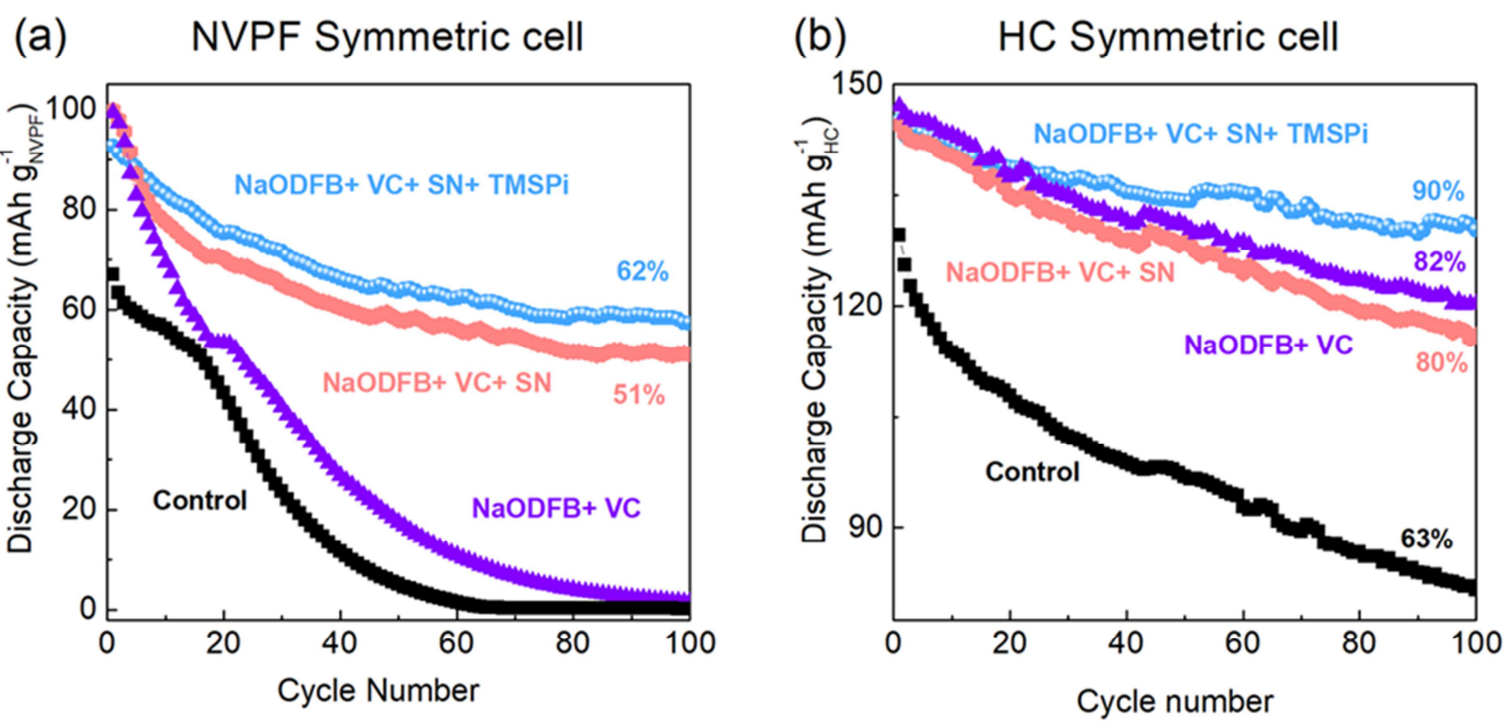

Figure 5. Discharge capacity as a function of cycle number for the cells using control electrolyte, and with the additives $0.5 \mathrm{wt} \% \mathrm{NaODFB}, 0.5 \mathrm{wt} \% \mathrm{NaODFB}+3 \mathrm{wt} \% \mathrm{VC}, 0.5 \mathrm{wt} \% \mathrm{NaODFB}+3 \mathrm{wt} \% \mathrm{VC}+3 \mathrm{wt} \%$ $\mathrm{SN}$, and $0.5 \mathrm{wt} \% \mathrm{NaODFB}+3 \mathrm{wt} \% \mathrm{VC}+3 \mathrm{wt} \% \mathrm{SN}+0.2 \mathrm{wt} \% \mathrm{TMSPi}$ in (a) NVPF and (b) HC symmetric cells cycled at $25^{\circ} \mathrm{C}$ with $\mathrm{C} / 5$ rate.

Turning to hard carbon symmetric cells, surprisingly, the degradation is not as dependent as for NVPF cells (Figure 5b). With inclusion of additives nearly $80-90 \%$ of the initial capacity is retained even after 100 cycles in $\mathrm{HC}$ symmetric cells as compared to 50 to $60 \%$ for the NVPF cells. A stable performance is observed with $\mathrm{NaODFB}+\mathrm{VC}$ additives itself and betterment in stability is obtained with $\mathrm{NaODFB}+\mathrm{VC}+\mathrm{SN}+\mathrm{TMSPi}$. The stability in $\mathrm{HC}$ symmetric cell cycling indicates the good SEI which prevents further electrolyte reduction and SEI growth. Altogether, the observed degradation with NaODFB+ VC is sufficient in creating good SEI but still NVPF/HC full cell shows capacity decay due to poor oxidative stability of the electrolyte. Addition of SN protects the NVPF surface hence reduce electrolyte oxidation. The additive 
TMSPi helps in further improving the SEI stability hence the electrolyte with NaODFB+ VC+ SN+ TMSPi shows the best stability with respect to both SEI and CEI.

\subsection{Practicality of the proposed electrolyte:}

For the sake of completion, we discuss next the practicality of the electrolyte formulation with additives $\mathrm{NaODFB}+\mathrm{VC}+\mathrm{SN}+\mathrm{TMSPi}$ that show the best optimized performance overall. First, the ionic conductivity is measured and the values obtained are slightly lower than the control electrolyte, 5.9, 10.49 and $15.8 \mathrm{mS} \mathrm{cm}^{-1}$ at 0,25 and $55{ }^{\circ} \mathrm{C}$ respectively. Cycling experiments were then conducted in 2032 coin cells at 0,25 and $55{ }^{\circ} \mathrm{C}$ (Figure 6a-c). Whatever the temperature, the electrolyte showed good electrochemical performance with only $3 \%$ capacity loss and $100 \%$ recovery (Figure $6 \mathrm{~d}$ ) at both 0 and $25^{\circ} \mathrm{C}$, after self-discharge tests for 1 week at $100 \%$ SOC ( $4.3 \mathrm{~V}$, after the removal of $2 \mathrm{Na}$ from NVPF). When raising the temperature to 55 ${ }^{\circ} \mathrm{C}$ the cells showed nearly $10 \%$ capacity loss during rest for 1 week with the recovery of $96 \%$ capacity. The capacity retention plots in Figure 6e shows stable capacity retention before and after self-discharge. In order to validate the knowledge transfer from coin cells to prototype cylindrical cells, we also assembled 18650 cells using our proposed electrolyte. The cells are initially formatted at $55{ }^{\circ} \mathrm{C}$ by charging at $\mathrm{C} / 10$ rate for one charge $(4.3 \mathrm{~V})$ and then allowed for cycling at $\mathrm{C} / 5$ for 10 cycles followed by self-discharge test for 1 week and recovery cycles using same rate. The experiments are conducted at both $25^{\circ} \mathrm{C}$ (Figure 6f) and $55{ }^{\circ} \mathrm{C}$ (Figure $6 \mathrm{~g}$ ) and similar results as that of coin cells were obtained with 18650 cells. The cell exhibited $\sim 9 \%$ capacity recovery even at $55{ }^{\circ} \mathrm{C}$ after 1 week rest at full SOC $(4.3 \mathrm{~V})$. The long cycling performance was tested at $1 \mathrm{C}$ rate and are shown in Figure $6 \mathrm{f}$ and $\mathrm{g}$. 

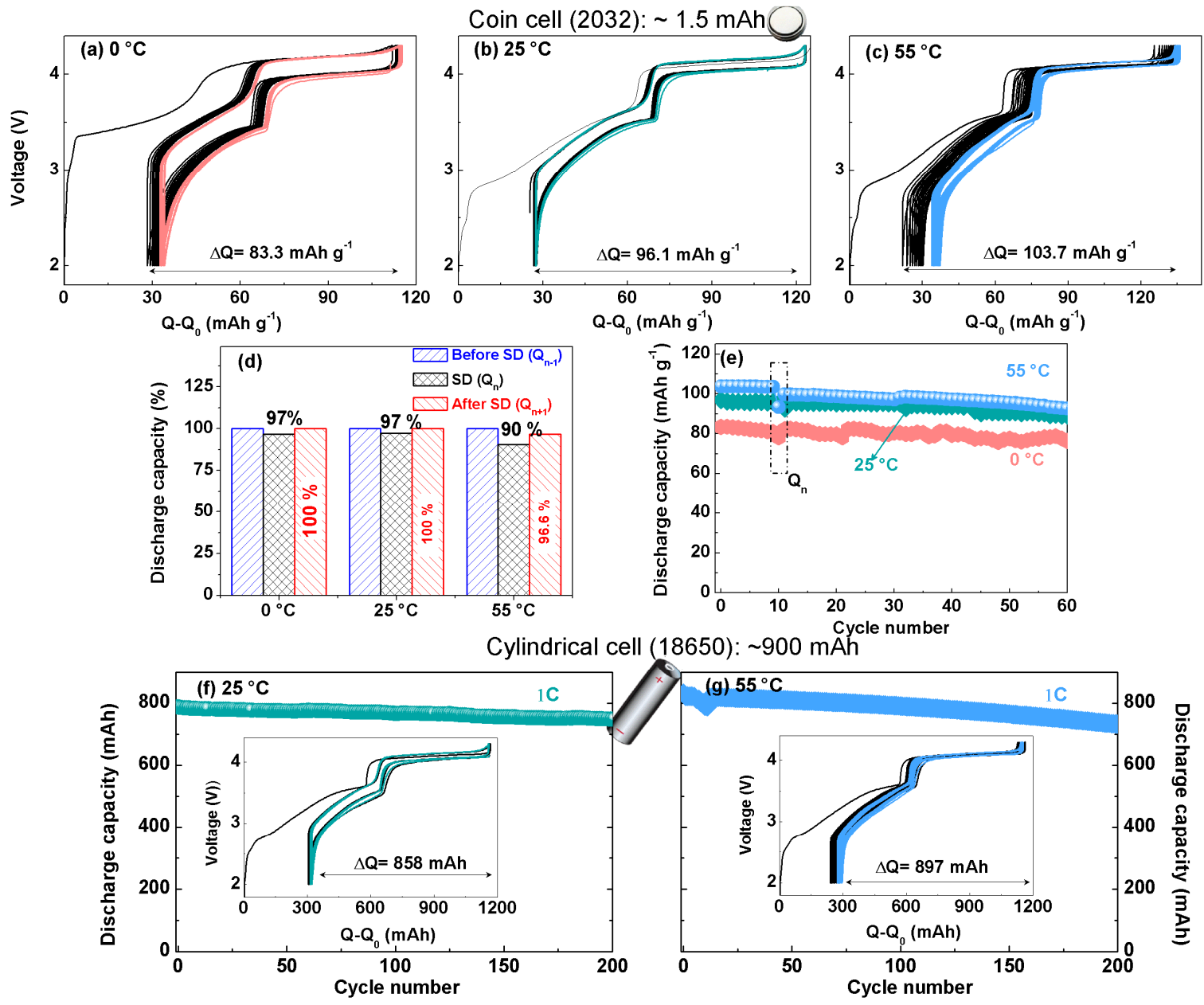

Figure 6. Electrochemical performance of $\mathrm{NVPF} / \mathrm{HC}$ cells using the electrolyte $1 \mathrm{M} \mathrm{NaPF}_{6}$ in 1: $1: 1 \mathrm{EC}$ : PC: DMC containing $0.5 \mathrm{wt} \% \mathrm{NaODFB}, 3 \mathrm{wt} \% \mathrm{VC}, 3 \mathrm{wt} \% \mathrm{SN}$ and $0.2 \mathrm{wt} \%$ TMSPi additives. (a- e) Data derived by testing in coin type 2032 cells; the cells are cycled at constant at temperatures of (a) 0 , (b) 25 and (c) $55^{\circ} \mathrm{C}$. (d) The comparison of discharge capacity observed before self-discharge test $\left(\mathrm{Q}_{\mathrm{n}-1}\right)$, in self-discharge cycle $\left(\mathrm{Q}_{\mathrm{n}}\right)$ and after self-discharge test $\left(\mathrm{Q}_{\mathrm{n}+1}\right)$. (e) Capacity retention plot where the $10^{\text {th }}$ cycle capacity is due to self-discharge test. (f and g) Data derived from 18650 cells; Capacity retention at $1 \mathrm{C}$ of the cells cycled at (a) $25{ }^{\circ} \mathrm{C}$, (b) $55{ }^{\circ} \mathrm{C}$; the data are derived after the self-discharge test where the cells were cycled minimum 20 cycles and also allowed to rest for 1 week at $100 \%$ SOC. The inset in each plot show the cycling profile for formation cycle (black) and after self-discharge test (green for $25^{\circ} \mathrm{C}$ and blue for $55^{\circ} \mathrm{C}$ ) in which the cells were cycled at $\mathrm{C} / 5$ rate.

Another figure of merit for practical application is safety of the battery together with its gassing that should remain minimum. This issue is more acute here, as VC and in few studies TMSPi were reported to be leading to gassing in Li-ion batteries ${ }^{[48,49]}$. To evaluate gassing, we carried out online electrochemical mass spectrometry (OEMS) studies in which specially designed cells 
were assembled using NVPF and HC electrodes. Two different electrolytes were studied, where the first one consists of $1 \mathrm{M} \mathrm{NaPF}_{6}$ in EC: PC: DMC and additives $0.5 \mathrm{wt} \% \mathrm{NaODFB}+3 \mathrm{wt} \%$ $\mathrm{VC}+3 \mathrm{wt} \% \mathrm{SN}$ without TMSPi, and a second one having the same composition but with $0.2 \mathrm{wt}$ \% TMSPi. The cells were cycled at $55^{\circ} \mathrm{C}$ using $\mathrm{C} / 10$ rate and the evolved gases during cycling were analyzed using mass spectrometer in which signals corresponding to $\mathrm{CO}_{2}, \mathrm{H}_{2}$ and $\mathrm{C}_{2} \mathrm{H}_{4}$ gases were calibrated. The $\mathrm{POF}_{3}$ and trimethylfluorosilane (TMSF) gases, which are reported as side-products from $\mathrm{NaPF}_{6}$ decomposition and TMSPi reaction with fluoride ion, respectively, were also recorded but not quantified.

The results are compiled in Figure $7 \mathrm{a}$.small amount of $\mathrm{POF}_{3}$ and TMSF were spotted only for electrolyte containing TMSPi in the first cycle, in agreement with literatures where the TMSPi is reported to induce $\mathrm{PF}_{6}^{-}$decomposition ${ }^{[49]}$. In addition, we note similar amount of $\mathrm{C}_{2} \mathrm{H}_{4}$ gas produced, irrespective of the presence or absence of TMSPi in the electrolyte. This is in line with limited EC reduction as the SEI is mainly formed from the reduction of NaODFB and VC. However, the NVPF/HC cell containing the electrolyte with $\mathrm{NaODFB}+\mathrm{VC}+\mathrm{SN}$ is associated with huge evolution of $\mathrm{CO}_{2}$ gas during SEI formation $(<3.8 \mathrm{~V})$. The amount of released $\mathrm{CO}_{2}$ is reduced nearly by five-fold with the addition of TMSPi. On the other hand, the $\mathrm{H}_{2}$ amount is not significantly affected by the presence of TMSPi, suggesting a separate process that is most probably related to reduction of protic species on the anode ${ }^{[50]}$. Overall, though TMSPi leads to small amount of $\mathrm{POF}_{3}$ and TMSF gases in the first cycle, it helps to drastically reduce the $\mathrm{CO}_{2}$ amount, which is likely caused by synergetic effects between TMSPi and the rest of the electrolyte additives.

The aforementioned gassing results are quite surprising as we observed huge gassing while using the electrolyte containing $\mathrm{NaODFB}+\mathrm{VC}+\mathrm{TMSPi}$ additives reported from our group 
previously $^{[24]}$. Worth to mention, such vigorous gassing was observed mainly in 18650 cells where the used active material amount was much higher than the coin type or OEMS cells $(\sim 20$ mg of NVPF for OEMS cells vs $9 \mathrm{~g}$ for 18650 cells) and when the cells were cycled at $55^{\circ} \mathrm{C}$ for long cycling. Due to difficulties in performing long-term cycling of the OEMS cells, we have used once again optical sensors to follow the pressure evolution upon long cycling. For this purpose, the 18650 cells were integrated with microstructured optical fiber (MOF-FBG) that is sensitive to hydraulic pressure in addition with single mode optical fibers (SMF- FBG) that are poorly sensitive to pressure changes.

The results were compared together in order to calculate the pressure changes (see experimental methods) upon cycling. The data in Figure $7 \mathrm{~b}$ compares the change in pressure as a function of cycle number for two different electrolyte formulations, namely NaODFB $+\mathrm{VC}+\mathrm{TMSP}$ that is similar to our previous report ${ }^{23}$ and $\mathrm{NaODFB}+\mathrm{VC}+\mathrm{SN}+\mathrm{TMSPi}$ discussed in this manuscript. The cells without $\mathrm{SN}(\mathrm{NaODFB}+\mathrm{VC}+\mathrm{TMSPi})$ exhibited gradual increase in cell pressure and lead to CID break when the pressure reaches the maximum limit of $\sim 16$ bars inside the cell. In contrast, the electrolyte containing $\mathrm{SN}$ in its formulation $(\mathrm{NaODFB}+\mathrm{VC}+\mathrm{SN}+\mathrm{TMSPi})$ showed much less change in pressure re-confirming the low amount of gassing observed with this electrolyte formulation. The main difference between the two studied electrolytes in Figure $7 \mathrm{~b}$ is the presence or absence of SN. It is known from the symmetric cells studies (Figure 5a) that SN protects the positive electrode. It indicates that the huge gassing observed in absence of SN comes from electrolyte oxidation leading to in-built pressure increase and deterioration in cell performance. 
(a) OEMS analyses: NaODFB+ VC+ SN

Without TMSPi

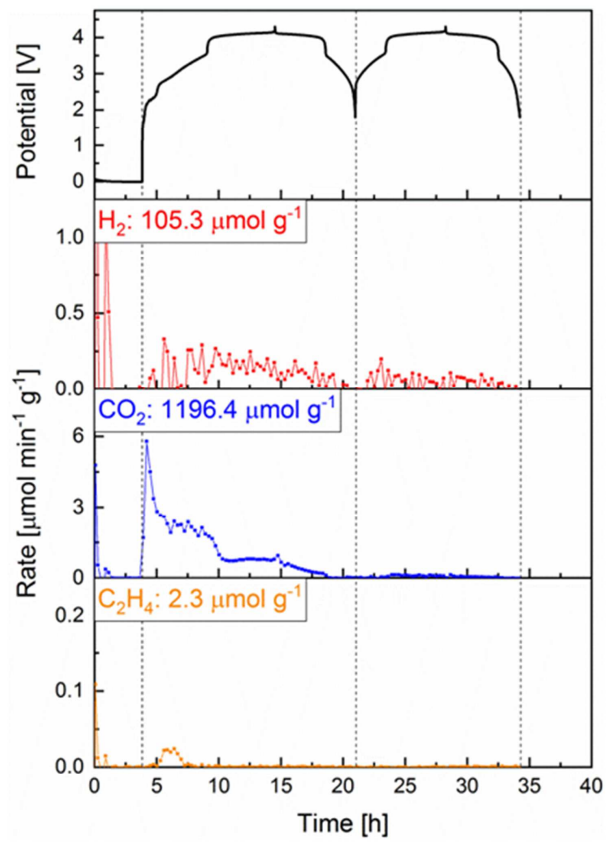

With TMSPi

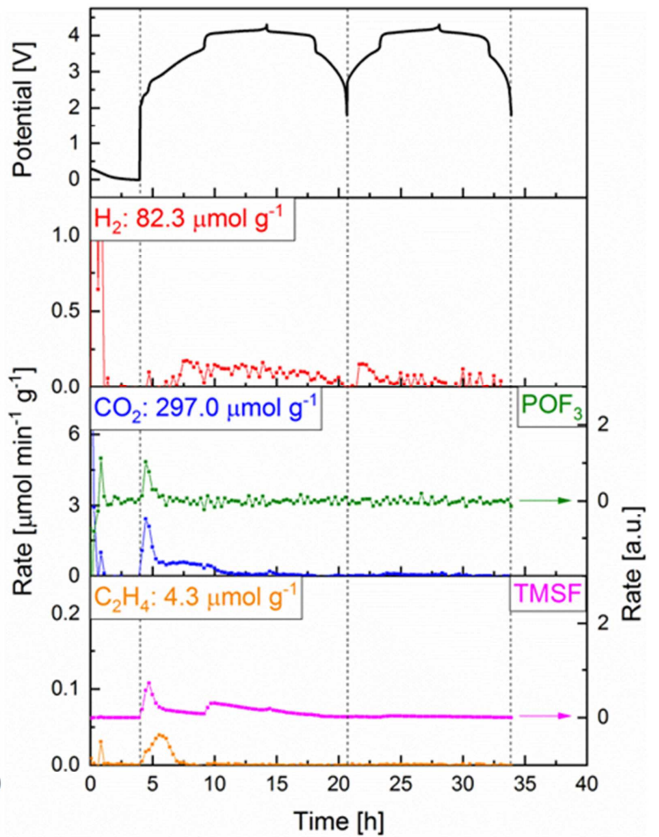

(b) Pressure analyses via optical sensing

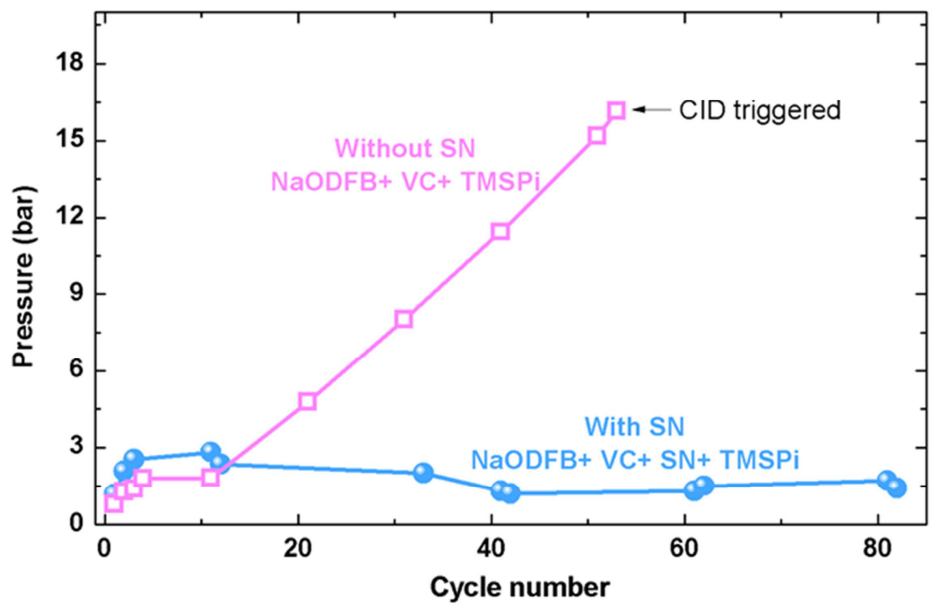

Figure 7. (a) OEMS analyses of the NVPF/HC cells using $1 \mathrm{M} \mathrm{NaPF}_{6}$ in EC: PC: DMC and electrolyte additives $\mathrm{NaODFB}+\mathrm{VC}+\mathrm{SN}$ without (left) and with (right) TMSPi added to the electrolyte. The numbers in each panel represent the total amount of $\mathrm{H}_{2}, \mathrm{CO}_{2}$ and $\mathrm{C}_{2} \mathrm{H}_{4}$ gases evolved from the cell during cycling. The gases $\mathrm{POF}_{3}$ and TMSF were observed only when TMSPi was used in the electrolyte and were not quantified. (b) The change in cell pressure (followed by FBGs) of the NVPF/ HC cylindrical 18650 cells upon cycling at $55{ }^{\circ} \mathrm{C}$ using $\mathrm{C} / 10$ rate. The electrolyte consist of $1 \mathrm{M} \mathrm{NaPF}_{6}$ in 1: 1: $1 \mathrm{EC}$ : PC: DMC where the additives used are $\mathrm{NaODFB}+\mathrm{VC}+\mathrm{TMSPi}$ with (blue circles) and without SN (pink squares). 


\section{Conclusion}

Altogether, the electrolyte $1 \mathrm{M} \mathrm{NaPF}_{6}$ in EC: PC: DMC consisting of the studied 4 electrolyte additives 0.5 wt $\%$ NaODFB, 3 wt \% VC, 3 wt \% SN and 0.2 wt \% TMSPi conjointly exhibited a stable SEI/ CEI formation that reflected in their electrochemical performance. The symmetric cell studies showed that the electrolyte with no additive deteriorates quite fast and the effect is more prominent in the NVPF electrode. The pronounced electrolyte oxidation together with SEI/CEI dissolution and loss in $\mathrm{Na}^{+}$inventory lead to faster self-discharge during rest. Consequently, the usage of electrolyte additives to stabilize both CEI and SEI becomes essential.

At present, the trial and error method has been the choice of researchers to come up with best electrolyte combinations. Though it is very useful, it calls for vast amount of experiments in order to achieve effective comparison. Further, translating the knowledge obtained from one material to others is not feasible without the deeper understanding of the role of electrolyte additives. Different post-mortem analyses techniques are in use to identify the nature of formed interphases and postulate the possible interfacial reactions. However, operando techniques are expected to provide more direct information.

The sensing analyses to follow the heat evolutions during cycling seems to be a viable technique to understand the interfacial reactions as most of the electrolyte redox processes are exothermic. The information obtained helps to screen the additives depending on the requirement. The ideal case will be to study the additive reactivity as a function of its stoichiometry, C-rate and temperature to determine the reaction kinetics which in turn can be an input data file to predict the interfacial reactions. At present, theoretical calculations are available to predict redox potential and energy of the different electrolyte additives. However, the prediction becomes complex when many additives that can work in synergy have to be used together. In such case, 
we believe that the heat evolutions measured from sensing experiments together with their redox potential can serve as an information source for predicting the exact interfacial reactions. By coupling the temperature studies with pressure analysis which is feasible using specially designed sensors we could provide much more information about the associated gassing and pressure increase.

In short, we have identified a new electrolyte composition for achieving highly performing 18650 $\mathrm{Na}$-ion cells based on the $\mathrm{NVPF} / \mathrm{HC}$ chemistry via operando optical calorimetry combined to an arsenal of electrochemical tests and OEMS measurements. This provides an attractive methodology to design efficient electrolytes for specific electrodes and we hope that the battery community will from now on consider such a new sensing tool to interrogate interphase formation and other the cascade reactions in battery chemistries beyond $\mathrm{Na}$ or Li-ion.

\section{Experimental Procedure}

Electrolyte Preparation: All the electrolytes were prepared by dissolving one molar $\mathrm{NaPF}_{6}$ (Stella, Japan) in battery grade solvents (DoDochem, China) in the Ar-filled glovebox (MBraun MB200B). The solvent mixture EC- PC- DMC in 1: 1: 1 volume ratio was dried by molecular sieves (4 A, Sigma-Aldrich) till its water content lower than 5 ppm, confirmed by Karl-Fisher titration (Metrohm 899 coulometer). The additive NaODFB is prepared in-house as reported earlier and other additives Vinylene carbonate (TCI, Europe), Succinonitrile (Acros Organics), and Tris(trimethylsilyl) Phosphite (TCI, Europe) were purchased and used as such, except succinonitrile which is melted at $70{ }^{\circ} \mathrm{C}$ and weighed in liquid state.

Ionic conductivity Measurement: Bulk ionic conductivity of the electrolyte solutions were measured using a Mettler Toledo S230 conductivity meter. Before the measurement, the conductivity probe was calibrated using a standard solution of conductivity $12.88 \mathrm{mS} . \mathrm{cm}^{-1}$ at 25 ${ }^{\circ} \mathrm{C} .3 \mathrm{~mL}$ of the electrolyte was taken in a brown glass vial and was then placed in a temperaturecontrolled bath. Conductivity was measured at $0^{\circ} \mathrm{C}, 25^{\circ} \mathrm{C}$ and $55^{\circ} \mathrm{C}$. At each temperature step, a 
constant temperature was maintained for at least $20 \mathrm{~min}$ to allow the electrolyte temperature to equilibrate with the bath temperature.

Electrochemical testing of NVPF/HC coin cells: $\mathrm{Na}_{3} \mathrm{~V}_{2}\left(\mathrm{PO}_{4}\right)_{2} \mathrm{~F}_{3}$ and hard carbon coated on $\mathrm{Al}$ foil were received from Tiamat, France. The electrodes were specially coated only on one side of the $\mathrm{Al}$ foil for conducting the studies in coin cells, however they are designed to have exact mass loading as in cylindrical 18650 cells. The electrode thickness, active material to conducting carbon and binder ratio, porosity etc were maintained the same as in 18650 cells. All of the electrodes were dried in a Buchi oven under vacuum (lower than $100 \mathrm{mbar}$ ) at $80^{\circ} \mathrm{C}$ for $12 \mathrm{~h}$ prior to being transferred into the glovebox. The electrochemical performance of NVPF/HC full cells were evaluated in 2032- type coin cells separated by two layers of glass fiber containing 150 $\mu \mathrm{L}$ of desired electrolytes. All cells were galvanostatically cycled by using MPG2 potentisostat or BCS battery cycler (Bio-Logic, France) at $55{ }^{\circ} \mathrm{C}$, and the cycling rates were calculated with respect to $\operatorname{NVPF}\left(1 \mathrm{C}=128 \mathrm{~mA} \mathrm{~g}^{-1}\right)$.

Sensing and Electrochemical testing of NVPF/HC cylindrical 18650 cells: Hermetically sealed NVPF/HC cylindrical 18650 cells without electrolyte were received from Tiamat, France. A 0.8 $\mathrm{mm}$ diameter hole was drilled into the negative pole of the dry, 18650 cells. The position was selected according to the welding point of the negative current collector, which was close to the center of the negative pole. This choice of the position helped in avoiding destruction of the jelly roll and in preventing the strain interaction between the FBG sensors and the jelly roll. All of the 18650 cells were dried in Buchi oven under vacuum at $80{ }^{\circ} \mathrm{C}$ for $12 \mathrm{~h}$ prior to being transferred into the glovebox. The 18650 cells were then filled with $5.5 \mathrm{~mL}$ of desired electrolyte inside the glovebox. Then the FBG sensors were inserted into the central void of the jelly roll through the drilled hole using a needle. The interface between the needle containing the FBG sensor and the 18650 cell was subsequently sealed with an epoxy that was cured for $24 \mathrm{~h}$; all processes were performed inside the glove box whose $\mathrm{O}_{2}$ and $\mathrm{H}_{2} \mathrm{O}$ content was maintained less than $0.1 \mathrm{ppm}$. Cells were cycled using BCS battery cycler (Bio-Logic, France) by keeping the cells inside an oven at $55^{\circ} \mathrm{C}$, and the cycling rates were calculated on the basis of NVPF material $(1 \mathrm{C}=128 \mathrm{~mA}$ $\mathrm{g}^{-1}$ ). Sensors were connected to FBGuard1550 (Safibra) or LUNA Si255 (Micron Optics) interrogator via optical fibres. The sampling period of the interrogator was set to $1 \mathrm{~s}$. According 
to the mentioned specifications, wavelength accurcy of the interrogators is $1 \mathrm{pm}$. The FBGs were purchased from SAMYON and calibrated before use.

Calibration of FBG sensors: The temperature calibration of the FBG sensors was conducted in the temperature ovens (IPP110, Memmert) after being inserted into the 18650 cells, from $55{ }^{\circ} \mathrm{C}$ to $45{ }^{\circ} \mathrm{C}$ in $5^{\circ} \mathrm{C}$ increments. The thermal rate constant, $k_{\mathrm{T}}$, was then linearly fitted according to the equation, $\Delta \lambda_{\mathrm{B}}=k_{\mathrm{T}} \Delta T$ with $\Delta \lambda_{\mathrm{B}}$ and $\Delta T$ being the Bragg wavelength shift and the temperature change, respectively.

Calibration of optical sensing calorimetry: According to the zero-dimensional thermal model (see Figure S2a in the Supporting Information), the heat generation rate of the cell, $\dot{Q}$, can be calculated by

$$
\dot{Q}=M C_{P} \frac{d T}{d t}+\dot{q}
$$

where $M$ is the mass of the cell, $C_{P}$ is cell's specific heat capacity, $T$ is the spatially average temperature of the cell, and $t$ is the time, and $\dot{q}$ is the heat dissipation rate of the cell to the environment. $T$ is estimated according to the geometry, the internal and the surface temperatures of the cell, see the details of the previous study ${ }^{[18]}$. The thermal model also gives

$$
\dot{q}=\frac{T_{\text {surface }}-T_{\text {ambient }}}{R_{\text {out }}}
$$

where $T_{\text {surface }}$ and $T_{\text {ambient }}$ are the temperatures at the surface of the cell and the ambient environment, respectively, and $R_{\text {out }}$ is the equivalent thermal resistance between the cell's surface and the ambient. To calculate the $\dot{Q}$ in real time, we determined the intrinsic parameters $\left(M C_{P}\right.$ and $R_{\text {out }}$ ) by applying an alternative galvanostatic pulse at a frequency of $2 \mathrm{~Hz}$ to the cell for producing known $\dot{Q}$ (see Figure S2b in the Supporting Information), zoomed view of the pulse is presented on the right part of Figure S2b (in the Supporting Information). Namely, because the sum of the reversible entropy terms over a cycle is zero, we calculated $\dot{Q}$ by the equation, $\dot{Q}=\oint_{\text {Cycle }} I V$, where the voltage $(V)$ and the current $(I)$ were recorded by the potentiostat. Together with the temporal temperature data, $R_{\text {out }}$ can be determined during the steady state (when $\frac{d T}{d t}=0$ and thus $\dot{Q}=\dot{q}$, see Figure S2c in the Supporting Information) by 
$R_{\text {out }}=\frac{T_{\text {surface }}-T_{\text {ambient }}}{\dot{q}}$ from Equation (2). In addition, $M C_{P}$ was then calculated in the transient state (Figure S2c in the Supporting Information) by linearly fitting $\dot{Q}-\dot{q}=M C_{P} \frac{d T}{d t}$ from Equation (1), where $\dot{q}$ was computed by the determined $R_{\text {out }}$ and Equation (2). Afterwards, we could derive $\dot{Q}$ under any electrochemical conditions according to Equations (1) and (2) by the operando temperature data and the pre-determined $M C_{P}$ and $R_{o u t}$.

Operando pressure monitoring via optical sensors: In order to examine the operando pressure accumulation in different electrolyte formulae, we simultaneously inserted a FBG in a single-ring suspended microstructured optical fiber (MOF-FBG) with a high pressure sensitivity $\left(k_{P, M O F}\right)$ of $-2.7 \mathrm{pm} \mathrm{bar}^{-1}$ and a FBG in a single-mode fiber (SMF-FBG) with a low pressure sensitivity $\left(k_{P, S M F}\right)$ of $-0.3 \mathrm{pm} \mathrm{bar}^{-1}$ into the 18650 , see more details in our previous work ${ }^{[18]}$. Due to the remarkable pressure sensitivity of MOF-FBG, the pressure change $(\Delta P)$ can be calculated as follows ${ }^{[18]}$.

$$
\Delta P=\frac{k_{T, S M F} \Delta \lambda_{B, M O F}-k_{T, M O F} \Delta \lambda_{B, S M F}}{k_{T, S M F} k_{P, M O F}-k_{T, M O F} k_{P, S M F}}
$$

where $k_{T, S M F}$ and $k_{T, M O F}$ are the thermal rate constants of SMF-FBG and MOF-FBG, respectively, and $\Delta \lambda_{B, S M F}$ and $\Delta \lambda_{B, M O F}$ are the Bragg wavelength shifts of SMF-FBG and MOFFBG, respectively

Electrochemical testing of NVPF and HC symmetric cell: Two NVPF-HC full cells with the same electrolyte were assembled in CR-2032 type coin cells inside an Ar-filled glovebox. Both the cells were cycled for one cycle to complete the formation of the cell. Then one of the two cells was charged to $4.3 \mathrm{~V}$ (constant current $\mathrm{CC}$ mode) and kept at $4.3 \mathrm{~V}$ (constant voltage $\mathrm{CV}$ mode) for 12 hours, another cell was kept at $2 \mathrm{~V}(\mathrm{CC}-\mathrm{CV})$. Both the cells were removed from the cycler at the same time and then decrimped inside the glovebox. The NVPF and HC electrodes removed from cell discharged to $2 \mathrm{~V}$ is used as +ve NVPF $\left(\mathrm{Na} \sim_{3} \mathrm{~V}_{2}\left(\mathrm{PO}_{4}\right)_{2} \mathrm{~F}_{3}\right)$ and -ve $\mathrm{HC}$ (de-sodiated HC). Similarly, NVPF and HC removed from cell charged to $4.3 \mathrm{~V}$ is used as -ve NVPF $\left(\mathrm{Na} \sim 1 \mathrm{~V}_{2}\left(\mathrm{PO}_{4}\right)_{2} \mathrm{~F}_{3}\right)$ and +ve HC (sodiated $\mathrm{HC}$ ). The +ve NVPF/-ve NVPF and +ve HC/-ve HC symmetric cells were assembled using the aforementioned electrode with the electrolyte formulation which was used in full cells to get these electrodes. The cells were cycled at room 
temperature at $\mathrm{C} / 5$ rate. All cells were duplicated and the results were compared only when the reproducibility was assured.

Online electrochemical mass spectrometry: Slurries comprising either $90 \mathrm{wt} \%$ of NVPF, $5 \mathrm{wt} \%$ of conductive carbon SC65, and $5 \mathrm{wt} \%$ of PVdF binder, or $80 \mathrm{wt} \%$ of $\mathrm{HC}, 10 \mathrm{wt} \%$ of conductive carbon SC65, and $10 \mathrm{wt} \%$ of PVdF binder were cast on an Al mesh and subsequently punched into electrode discs of $13 \mathrm{~mm}$ in diameter. In-house designed OEMS full cells were assembled in an Ar-filled glovebox with both $\mathrm{H}_{2} \mathrm{O}$ and $\mathrm{O}_{2}$ contents less than $0.1 \mathrm{ppm}$, using an NVPF disc as cathode, one piece of Whatman GF/D glassfibre as separator, an HC disc as anode, and $150 \mu \mathrm{L}$ of Na-based electrolyte. The cells were cycled between $1.8-4.3 \mathrm{~V}$ inside a temperature chamber at $55{ }^{\circ} \mathrm{C}$ using a current density of $12.8 \mathrm{~mA} \mathrm{~g}^{-1} . \mathrm{H}_{2}, \mathrm{CO}_{2}$, and $\mathrm{C}_{2} \mathrm{H}_{4}$ amounts were quantitatively measured by a quadrupole mass spectrometer (Pfeiffer, Switzerland), where the technical details can be found elsewhere ${ }^{[51]}$.

\section{Supporting Information}

Supporting Information is available from the Wiley Online Library or from the author.

\section{Acknowledgements:}

The authors thank the RS2E Network for funding as well as the financial support of Région Nouvelle Aquitaine, of the French National Research Agency (STORE-EX Labex Project ANR10-LABX-76-01). S. M acknowledges Horizon 2020 research and innovation program under grant agreement No 875629. J.-M.T. and J.H. acknowledge funding from the European Research Council (ERC) (FP/2014)/ERC Grant-Project 670116-ARPEMA and DIM RESPORE. P. D thanks RS2E for PhD funding. We thank Quentin LOISELEUX and John ABOU-RJEILY from TIAMAT, France for providing the NVPF/HC 18650 cells as well as the NVPF, HC electrodes for the study. We thank Jeff DAHN for providing VAWQuum software for the dV/dQ fitting. We thank Julien BONEFACINO, Steven T. BOLES, and Hwa-Yaw TAM for providing the microstructured optical fibers. 


\section{Conflict of interests}

The authors declare no conflict of interest. The electrolyte with additives NaODFB, VC, SN and

TMSPi is patented with patent application number EP21305354.9.

\section{References}

[1] R. Schmuch, R. Wagner, G. Hörpel, T. Placke, M. Winter, Nat. Energy 2018, 3, 267.

[2] D. Larcher, J.-M. Tarascon, Nat. Chem. 2015, 7, 19.

[3] M. Weil, S. Ziemann, J. Peters, in Behav. Lithium-Ion Batter. Electr. Veh. Battery Health Perform. Saf. Cost (Eds.: G. Pistoia, B. Liaw), Springer International Publishing, Cham, 2018, pp. 59-74.

[4] H. Hijazi, P. Desai, S. Mariyappan, Batter. Supercaps 2021, 4, 881.

[5] A. Bauer, J. Song, S. Vail, W. Pan, J. Barker, Y. Lu, Adv. Energy Mater. 2018, 8, 1702869.

[6] J. Song, B. Xiao, Y. Lin, K. Xu, X. Li, Adv. Energy Mater. 2018, 8, 1703082.

[7] K. Xu, Chem. Rev. 2004, 104, 4303.

[8] K. Xu, Chem. Rev. 2014, 114, 11503.

[9] X. Xia, M. N. Obrovac, J. R. Dahn, Electrochem. Solid-State Lett. 2011, 14, A130.

[10] R. Mogensen, D. Brandell, R. Younesi, ACS Energy Lett. 2016, 1, 1173.

[11] D. I. lermakova, R. Dugas, M. R. Palacín, A. Ponrouch, J. Electrochem. Soc. 2015, 162, A7060.

[12] S. S. Zhang, J. Power Sources 2006, 162, 1379.

[13] L. Cheng, R. S. Assary, X. Qu, A. Jain, S. P. Ong, N. N. Rajput, K. Persson, L. A. Curtiss, J. Phys. Chem. Lett. 2015, 6, 283.

[14] A. Benayad, J. E. Morales-Ugarte, C. C. Santini, R. Bouchet, J. Phys. Chem. A 2021, 125, 1069.

[15] R. Pigliapochi, S. Benders, E. V. Silletta, S. L. Glazier, E. Lee, J. Dahn, A. Jerschow, Batter. Supercaps $2021,4,322$.

[16] N. M. Trease, L. Zhou, H. J. Chang, B. Y. Zhu, C. P. Grey, Solid State Nucl. Magn. Reson. 2012, 42, 62.

[17] Y. Yuan, K. Amine, J. Lu, R. Shahbazian-Yassar, Nat. Commun. 2017, 8, 15806.

[18] J. Huang, L. Albero Blanquer, J. Bonefacino, E. R. Logan, D. Alves Dalla Corte, C. Delacourt, B. M. Gallant, S. T. Boles, J. R. Dahn, H.-Y. Tam, J.-M. Tarascon, Nat. Energy 2020, 5, 674.

[19] J. Chen, Z. Huang, C. Wang, S. Porter, B. Wang, W. Lie, H. K. Liu, Chem. Commun. 2015, 51, 9809.

[20] D. Aurbach, K. Gamolsky, B. Markovsky, Y. Gofer, M. Schmidt, U. Heider, Electrochimica Acta 2002, 47, 1423.

[21] Y.-S. Kim, T.-H. Kim, H. Lee, H.-K. Song, Energy Environ. Sci. 2011, 4, 4038.

[22] Y.-M. Song, J.-G. Han, S. Park, K. Tae Lee, N.-S. Choi, J. Mater. Chem. A 2014, 2, 9506.

[23] G. Yan, D. Alves-Dalla-Corte, W. Yin, N. Madern, G. Gachot, J.-M. Tarascon, J. Electrochem. Soc. 2018, 165, A1222.

[24] C. Cometto, G. Yan, S. Mariyappan, J.-M. Tarascon, J. Electrochem. Soc. 2019, 166, A3723.

[25] G. Yan, K. Reeves, D. Foix, Z. Li, C. Cometto, S. Mariyappan, M. Salanne, J.-M. Tarascon, Adv. Energy Mater. 2019, 9, 1901431.

[26] R. Fong, U. von Sacken, J. R. Dahn, J. Electrochem. Soc. 1990, 137, 2009.

[27] M. S. Ding, K. Xu, T. R. Jow, J. Electrochem. Soc. 2000, 147, 1688.

[28] M. S. Ding, K. Xu, S. Zhang, T. R. Jow, J. Electrochem. Soc. 2001, 148, A299.

[29] M. S. Ding, J. Electrochem. Soc. 2004, 151, A731.

[30] F. Leng, C. M. Tan, M. Pecht, Sci. Rep. 2015, 5, 12967.

[31] X. Zhang, R. Kostecki, T. J. Richardson, J. K. Pugh, P. N. Ross, J. Electrochem. Soc. 2001, 148, A1341.

[32] S. Grugeon, P. Jankowski, D. Cailleu, C. Forestier, L. Sannier, M. Armand, P. Johansson, S. Laruelle, J. Power Sources 2019, 427, 77. 
[33] A. L. Michan, Bharathy. S. Parimalam, M. Leskes, R. N. Kerber, T. Yoon, C. P. Grey, B. L. Lucht, Chem. Mater. 2016, 28, 8149.

[34] K. Ushirogata, K. Sodeyama, Y. Okuno, Y. Tateyama, J. Am. Chem. Soc. 2013, 135, 11967.

[35] G.-Y. Kim, J. R. Dahn, J. Electrochem. Soc. 2015, 162, A437.

[36] H. Zhi, L. Xing, X. Zheng, K. Xu, W. Li, J. Phys. Chem. Lett. 2017, 8, 6048.

[37] G.-Y. Kim, R. Petibon, J. R. Dahn, J. Electrochem. Soc. 2014, 161, A506.

[38] T. Yim, S.-G. Woo, S. H. Lim, W. Cho, J. H. Song, Y.-K. Han, Y.-J. Kim, J. Mater. Chem. A 2015, 3, 6157.

[39] Y.-K. Han, J. Yoo, T. Yim, J. Mater. Chem. A 2015, 3, 10900.

[40] I. Bloom, A. N. Jansen, D. P. Abraham, J. Knuth, S. A. Jones, V. S. Battaglia, G. L. Henriksen, J. Power Sources 2005, 139, 295.

[41] H. M. Dahn, A. J. Smith, J. C. Burns, D. A. Stevens, J. R. Dahn, J. Electrochem. Soc. 2012, 159, A1405.

[42] G. Yan, R. Dugas, J.-M. Tarascon, J. Electrochem. Soc. 2018, 165, A220.

[43] A. J. Smith, J. C. Burns, D. Xiong, J. R. Dahn, J. Electrochem. Soc. 2011, 158, A1136.

[44] E. R. Logan, H. Hebecker, X. Ma, J. Quinn, Y. HyeJeong, S. Kumakura, J. Paulsen, J. R. Dahn, J. Electrochem. Soc. 2020, 167, 060530.

[45] J. C. Burns, L. J. Krause, D.-B. Le, L. D. Jensen, A. J. Smith, D. Xiong, J. R. Dahn, J. Electrochem. Soc. 2011, 158, A1417.

[46] C. Shen, D. Xiong, L. D. Ellis, K. L. Gering, L. Huang, J. R. Dahn, J. Electrochem. Soc. 2017, 164, A3349.

[47] L. J. Krause, L. D. Jensen, J. R. Dahn, J. Electrochem. Soc. 2012, 159, A937.

[48] J.-Y. Eom, I.-H. Jung, J.-H. Lee, J. Power Sources 2011, 196, 9810.

[49] X. Qi, L. Tao, H. Hahn, C. Schultz, D. R. Gallus, X. Cao, S. Nowak, S. Röser, J. Li, I. Cekic-Laskovic, B. R. Rad, M. Winter, RSC Adv. 2016, 6, 38342.

[50] M. Metzger, B. Strehle, S. Solchenbach, H. A. Gasteiger, J. Electrochem. Soc. 2016, 163, A798.

[51] M. He, Elucidating Interface Reactions in Li-Ion Batteries and Supercapacitors by in Situ Gas Analysis, Doctoral Thesis, ETH Zurich, 2016. 


\section{Table of content entry:}

In-depth understanding of interfacial reactions between electrode and electrolyte can be achieved using operando monitoring of thermal events during interphase formation using optical sensors. The present study set an example for such analyses that together with complementary electrochemical analyses lead to identification of optimized electrolyte formulation for Na-ion batteries.

Parth Desai, Jiaqiang Huang, Hussein Hijazi, Leiting Zhang, Sathiya Mariyappan, ${ }^{*}$ and JeanMarie Tarascon ${ }^{*}$

Deciphering interfacial reactions via optical sensing to tune the interphase chemistry for optimized Na-ion electrolyte formulation

\section{$\underline{\text { ToC figure: }}$}

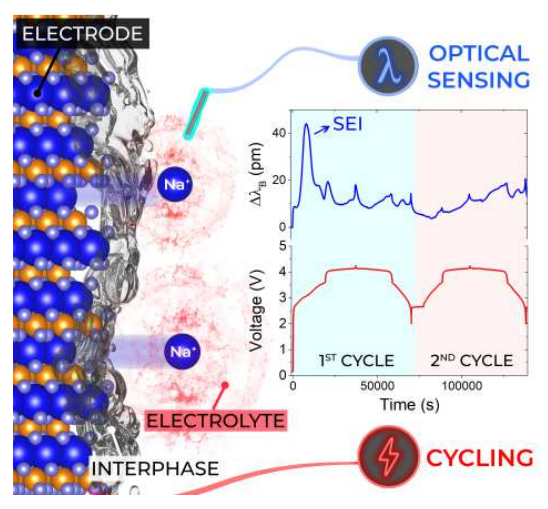




\section{Supporting Information}

Deciphering interfacial reactions via optical sensing to tune the interphase chemistry for optimized Na-ion electrolyte formulation

Parth Desai, Jiaqiang Huang, Hussein Hijazi, Leiting Zhang, Sathiya Mariyappan, ${ }^{*}$ and JeanMarie Tarascon*

\section{Supporting Figures.}

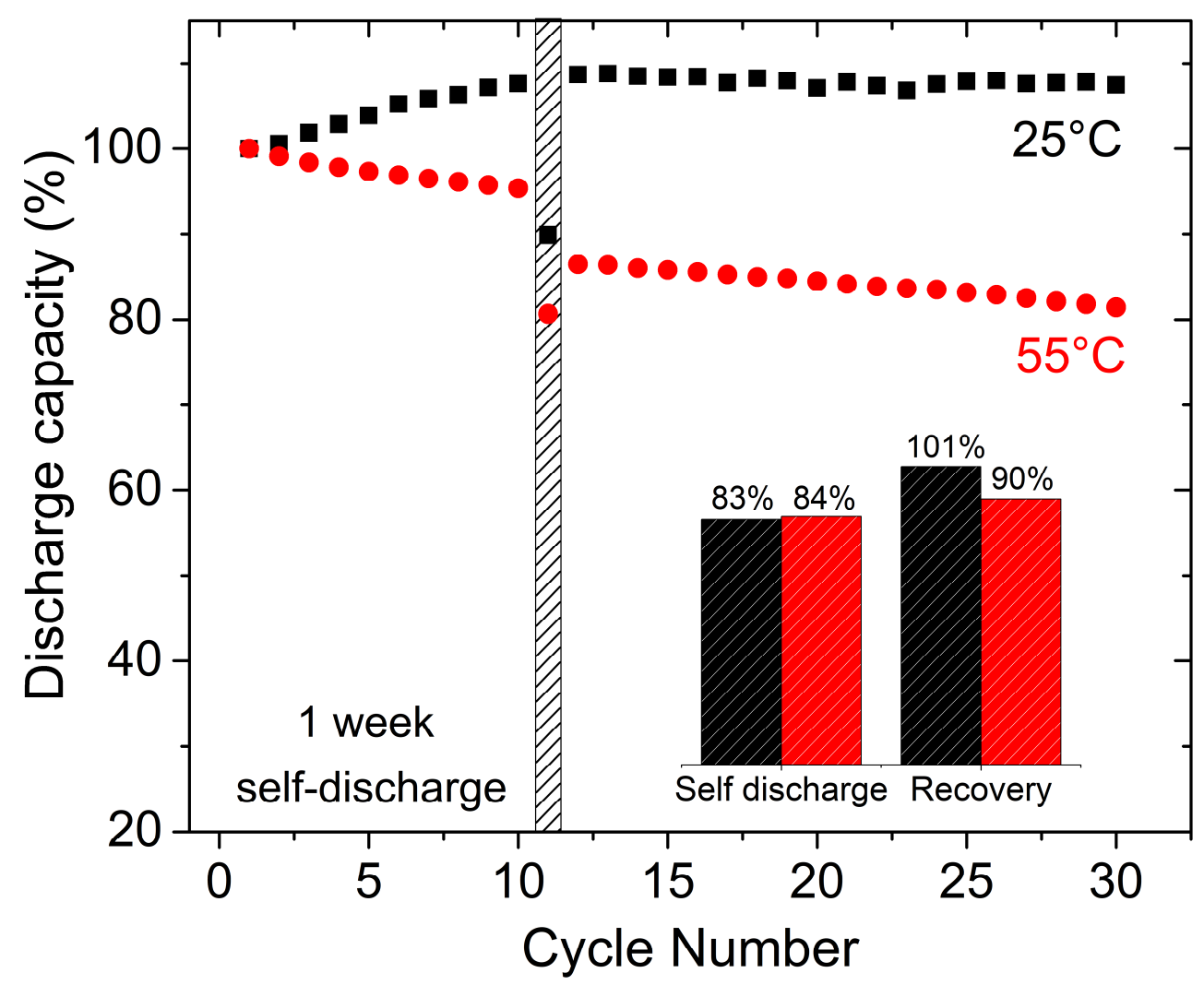

Figure S1. The percentage capacity retention vs. cycle number for $\mathrm{Na}_{3} \mathrm{~V}_{2}\left(\mathrm{PO}_{4}\right)_{2} \mathrm{~F}_{3}$ (NVPF) / hard carbon (HC) full cells using $1 \mathrm{M} \mathrm{NaPF}_{6}$ in EC: PC: DMC (1:1:1 by volume) as electrolyte. The cells were cycled at $\mathrm{C} / 5$ in a fixed temperature of $25^{\circ} \mathrm{C}$ and $55^{\circ} \mathrm{C}$ by keeping them in an oven maintained at the required temperature. The cells were cycled for 10 cycles after which allowed to rest (self-discharge test) at $100 \%$ SOC (4.3V) for 1 week. Discharge capacity of $10^{\text {th }}, 11^{\text {th }}$ and $12^{\text {th }}$ cycle is $Q_{10}, Q_{11}$ and $Q_{12}$ respectively. The percentage capacity observed just after self-discharge $\left(Q_{11} / Q_{10}\right)$ and in recovery cycle $\left(Q_{12} / Q_{10}\right)$ is presented in the histogram as inset in the Figure S1. Stable capacity retention with $100 \%$ recovery was observed at $25{ }^{\circ} \mathrm{C}$, while pronounced capacity decay with solely $90 \%$ recovery after self-discharge test was obtained at $55{ }^{\circ} \mathrm{C}$ indicating the comparatively poor performance of the electrolyte at high temperature cycling. 
a)

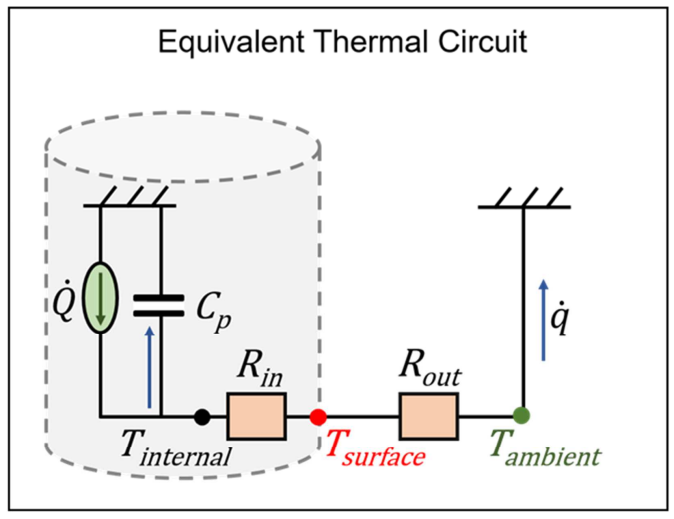

b)
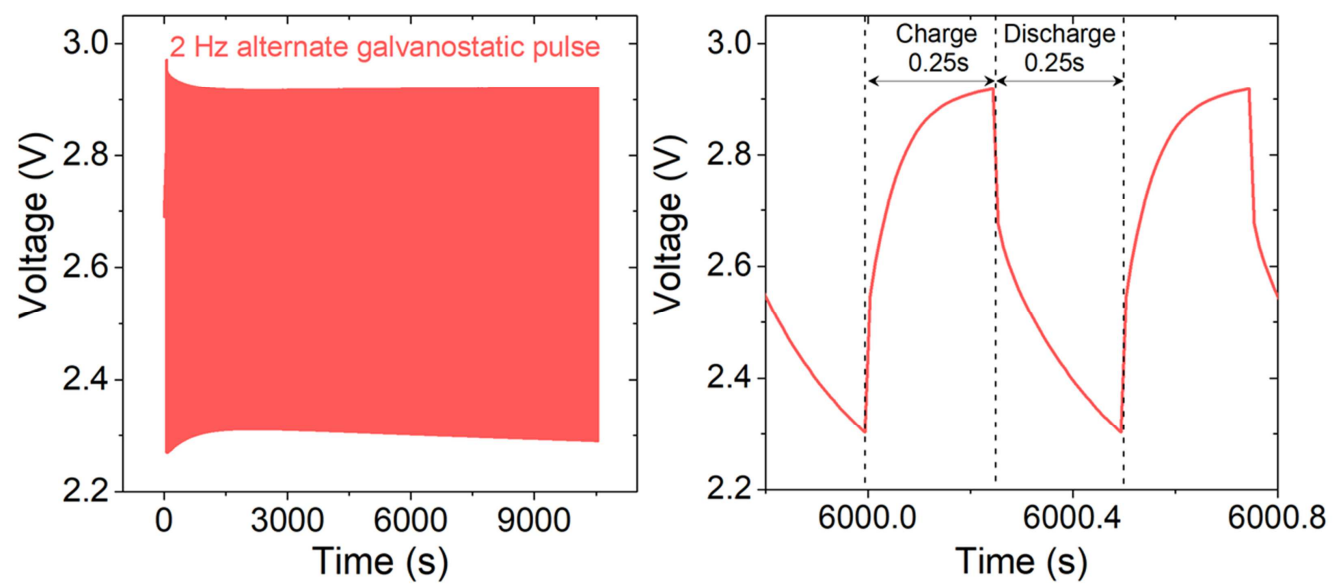

c)

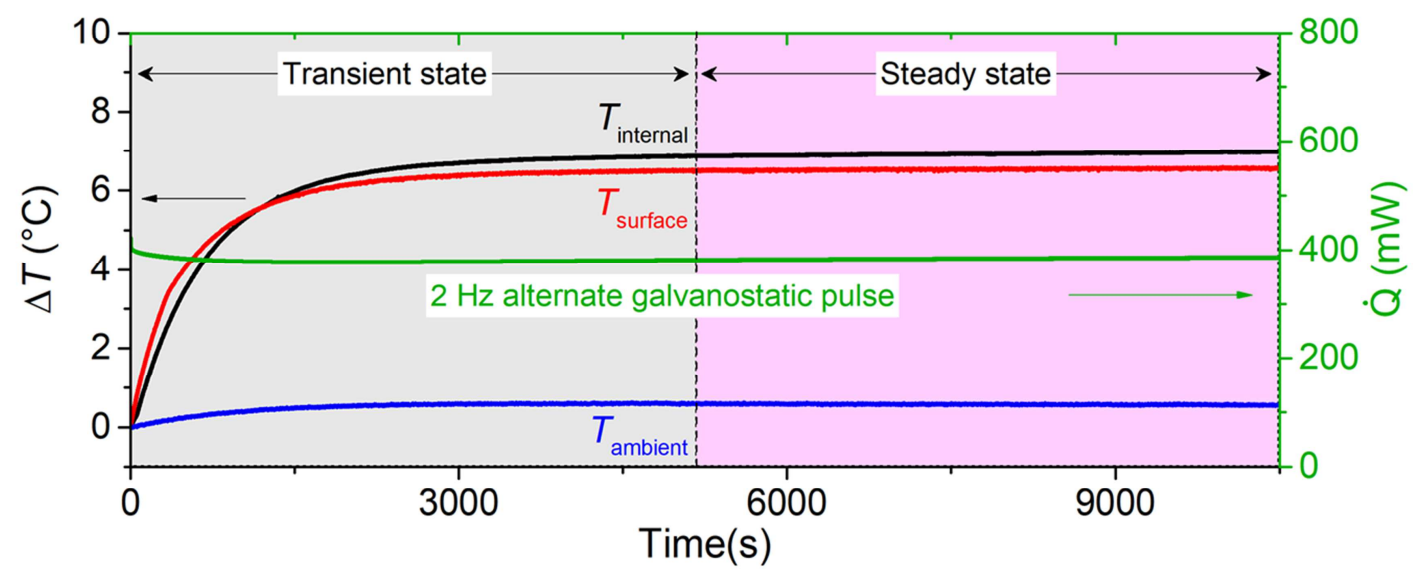

Figure S2. (a) Thermal equivalent circuit for zero dimensional thermal model used for sensing calorimetry. (b) The voltage vs. time behavior of NVPF/HC cylindrical 18650 cell during the alternative galvanostatic pulse at a frequency of $2 \mathrm{~Hz}$ is shown for the complete data (b, left) and for one full cycle (b, right). Applied current gives the rate of heat generation $(\dot{Q})$ and is calculated as $\dot{Q}=\oint_{c y c l e} I V$. (c) Thermal response corresponding to the applied galvanostatic pulse for ambient, surface and internal sensors. Temperature response is divided into transient state and steady state. $R_{\text {out }}$ is determined from steady state and then $M C_{P}\left(\sim 38 \mathrm{~J} \mathrm{~K}^{-1}\right)$ is calculated from the transient state (See Calibration of optical sensing calorimetry in Experimental Procedure for details). 


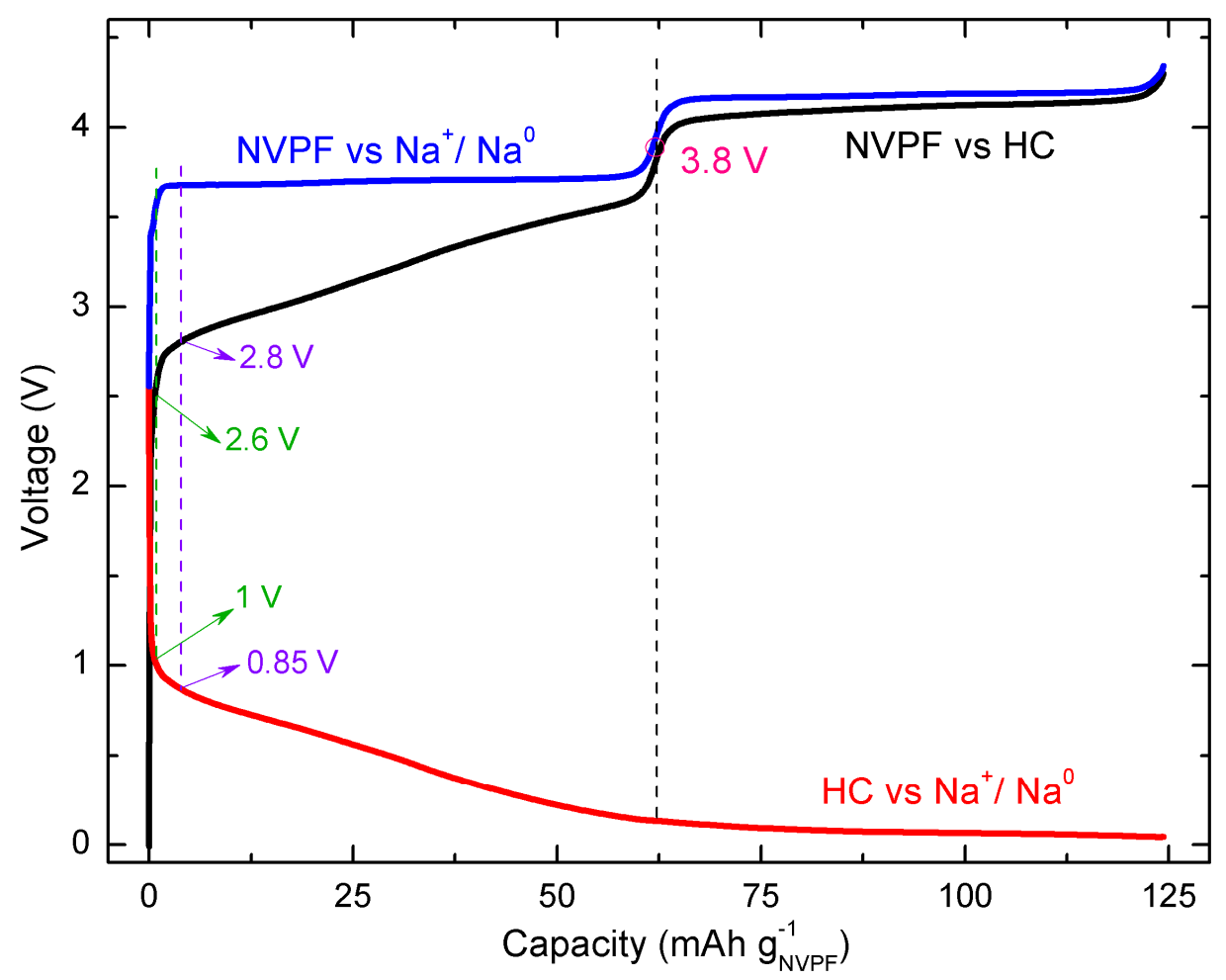

Figure S3. The three electrode cycling data of NVPF/HC cell where the cell was cycled using NVPF and $\mathrm{HC}$ as positive and negative electrodes respectively while a piece of sodium metal is used as the reference electrode. The black curve shows the potential evolution of the NVPF/HC cell as a function of capacity whereas blue and red curves represent the corresponding potential of individual electrodes (NVPF and HC) measured against sodium metal. For example, $2.6 \mathrm{~V}$ and $2.8 \mathrm{~V}$ in the NVPF/HC full cell nearly corresponds to $1 \mathrm{~V}$ and $0.85 \mathrm{~V}$ of $\mathrm{HC}$ versus $\mathrm{Na}$. Similarly, the $3.8 \mathrm{~V}$ in NVPF/HC cell corresponds to 1 sodium removal from NVPF. The capacity is measured with respect to the active material weight of NVPF. (Related to Figure 2) 


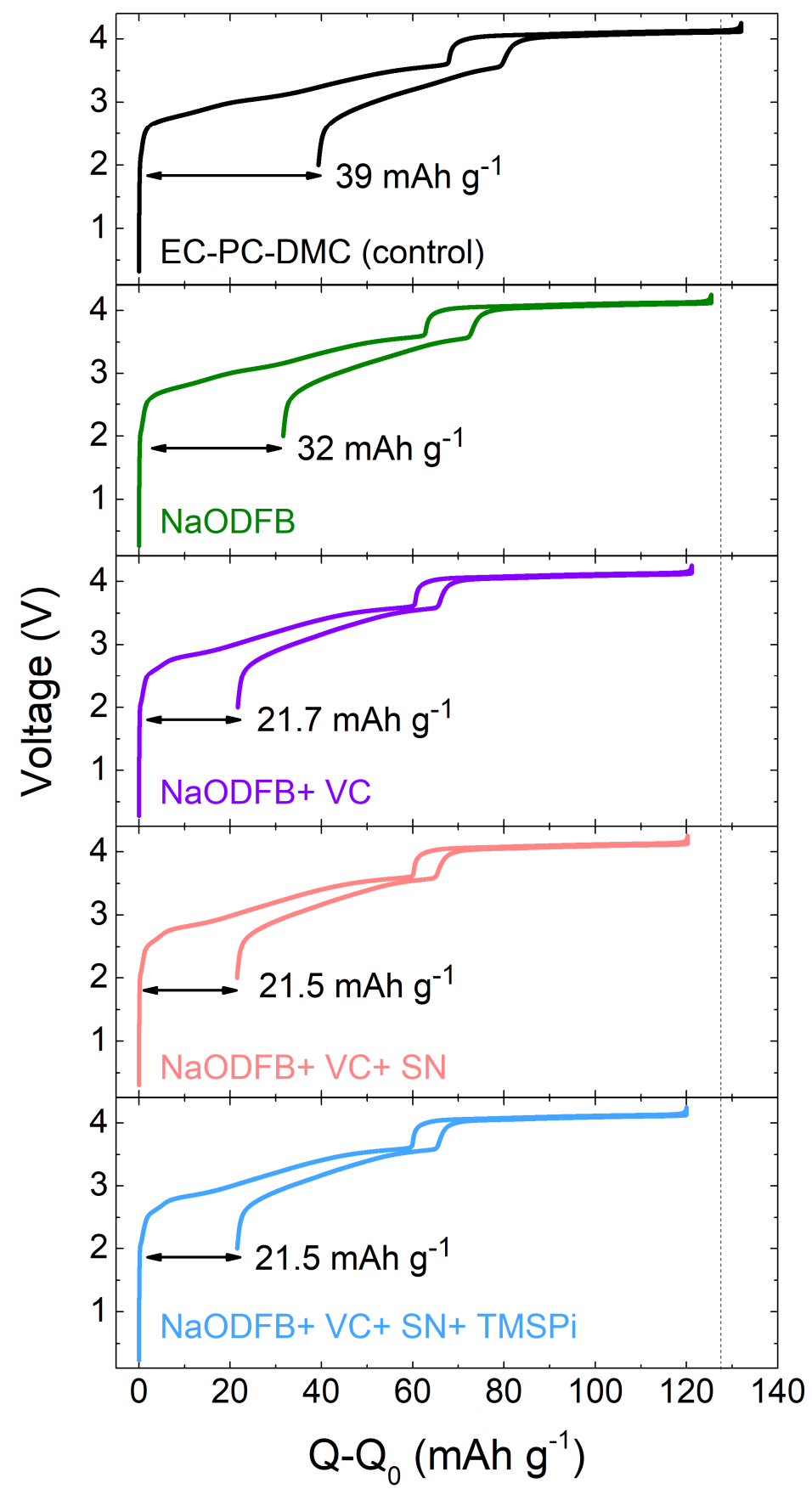

Figure S4. The $1^{\text {st }}$ cycle data of NVPF/HC cylindrical 18650 cells used for the sensing studies. Minimum 2 cells were assembled for each electrolyte formulation and the cells are kept in $55^{\circ} \mathrm{C}$ oven and cycled at $\mathrm{C} / 10$ rate. The electrolyte studied are the control electrolyte (1 $\mathrm{M} \mathrm{NaPF}_{6}$ in EC- PC- DMC 1: 1: 1 by volume) with no additive or having additives namely 0.5 wt $\%$ NaODFB, 0.5 wt $\%$ NaODFB+ 3 wt $\%$ VC, 0.5 wt $\% \mathrm{NaODFB}+3 \mathrm{wt} \% \mathrm{VC}+3 \mathrm{wt} \% \mathrm{SN}$ and $0.5 \mathrm{wt} \% \mathrm{NaODFB}+3 \mathrm{wt} \% \mathrm{VC}+3 \mathrm{wt} \% \mathrm{SN}+0.2 \mathrm{wt} \% \mathrm{TMSPi}$ respectively. The mentioned additive combinations are blended in control electrolyte and named using the additives present in that specific electrolyte formulation. The first cycle irreversible capacities are mentioned in the figures. The dotted line in the figure indicates the theoretical capacity limit of the cell. (Related to Figure 2). 
1.9- $3.8 \mathrm{~V}$
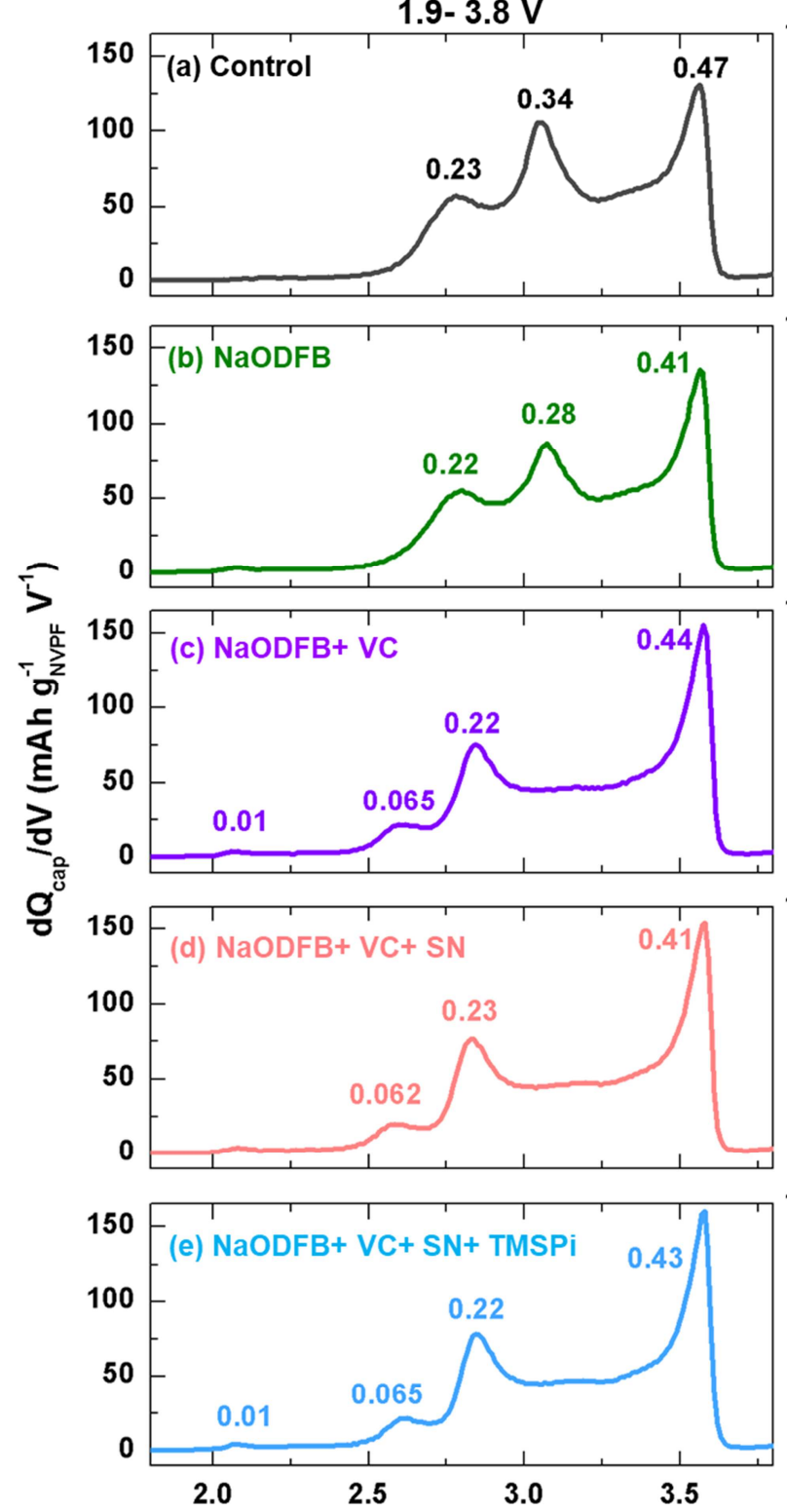

3.8- $4.25 \mathrm{~V}$
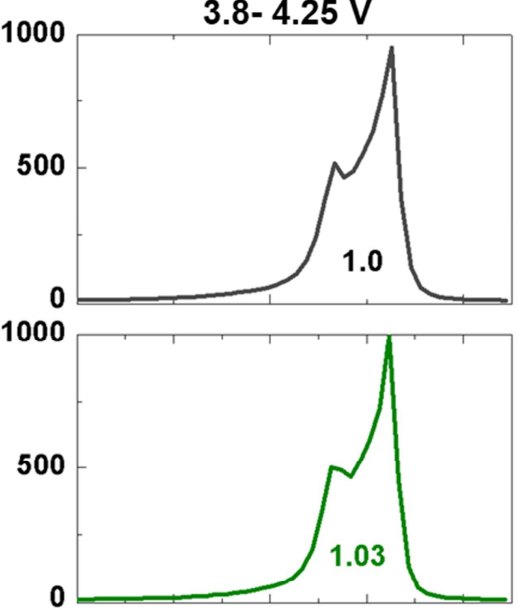

1000
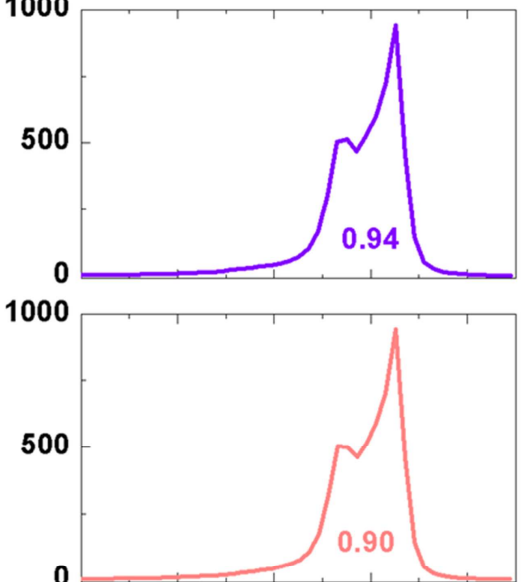

1000

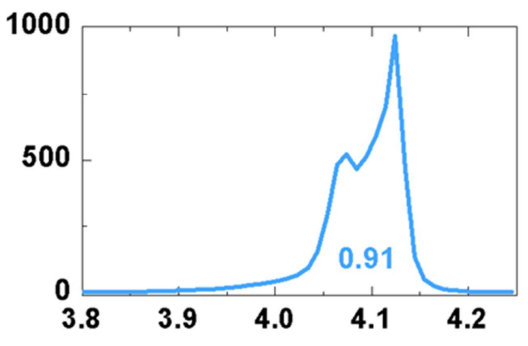

Voltage (V)

Figure S5. Capacity derivative $d Q_{c a p} / d V$ vs. voltage $(V)$ plots for the $1^{\text {st }}$ charge of the NVPF/HC cylindrical 18650 cells. The voltage region from OCV- 3.8 V are shown in left and 3.8- 4.25 V in right. The electrolyte studied are the control electrolyte $\left(1 \mathrm{M} \mathrm{NaPF}_{6}\right.$ in EC- PC- DMC 1:1:1 by volume) with no additive or having additives namely $0.5 \mathrm{wt} \%$ NaODFB, $0.5 \mathrm{wt} \%$ NaODFB+ $3 \mathrm{wt} \% \mathrm{VC}, 0.5 \mathrm{wt} \% \mathrm{NaODFB}+3 \mathrm{wt} \% \mathrm{VC}+$ $3 \mathrm{wt} \% \mathrm{SN}$ and $0.5 \mathrm{wt} \% \mathrm{NaODFB}+3 \mathrm{wt} \% \mathrm{VC}+3 \mathrm{wt} \% \mathrm{SN}+0.2 \mathrm{wt} \% \mathrm{TMSPi}$ respectively. Amount of $\mathrm{e}^{-}$ involved in the reaction corresponding to a particular peak is presented in the figure and is calculated with respect to NVPF. (Related to Figure 2) 


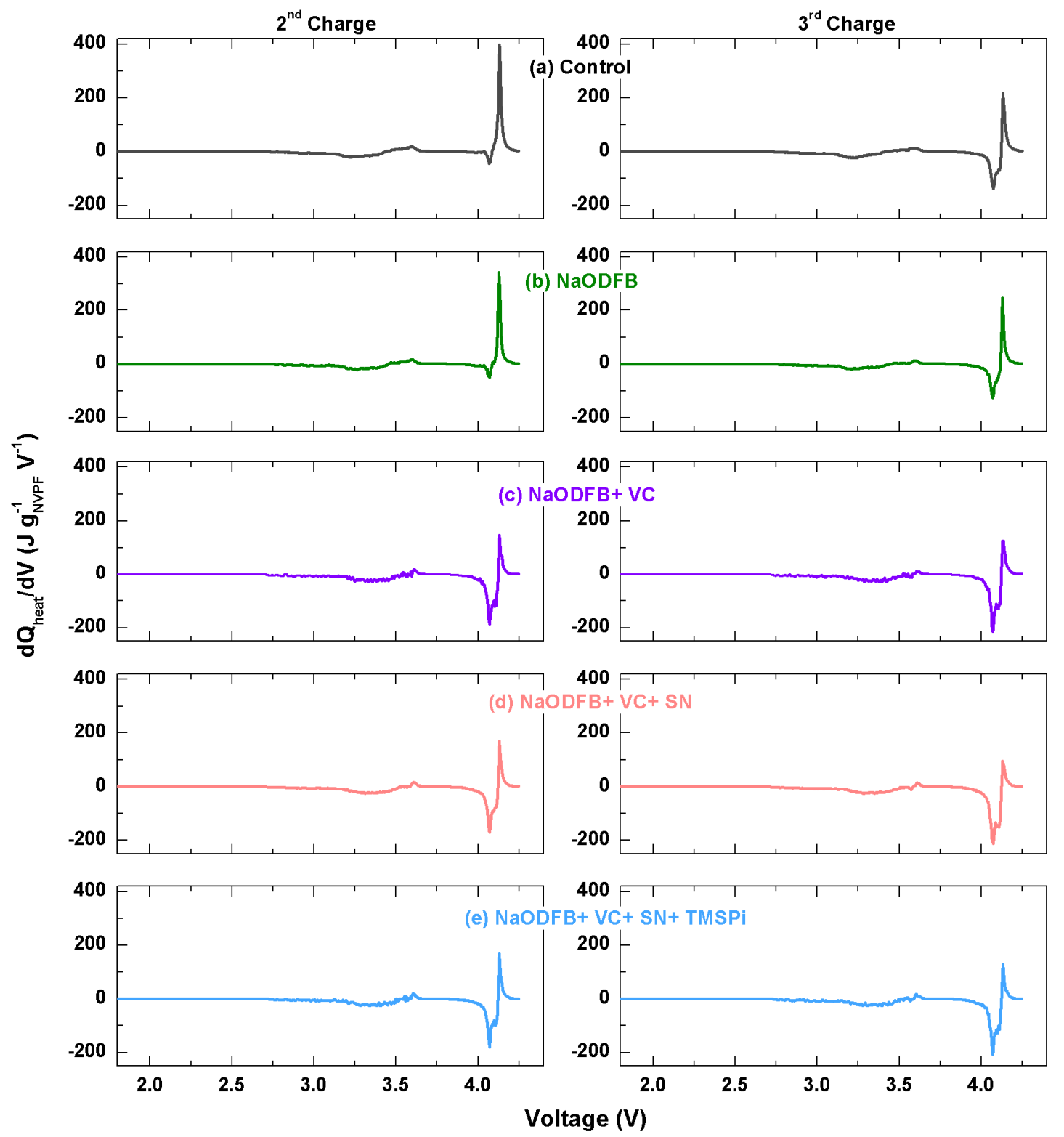

Figure S6. Derivative heat $d Q_{\text {neat }} / d V$ vs. voltage $(V)$ plots for the $2^{\text {nd }}$ and $3^{\text {rd }}$ charge of the NVPF/HC cylindrical 18650 cells cycled at $\mathrm{C} / 10$ in $55^{\circ} \mathrm{C}$ oven. The electrolyte studied are the control electrolyte $(1 \mathrm{M}$ $\mathrm{NaPF}_{6}$ in EC- PC- DMC 1: 1: 1 by volume) with no additive or having additives namely $0.5 \mathrm{wt} \%$ NaODFB, $0.5 \mathrm{wt} \% \mathrm{NaODFB}+3 \mathrm{wt} \% \mathrm{VC}, 0.5 \mathrm{wt} \%$ NaODFB+ $3 \mathrm{wt} \% \mathrm{VC}+3 \mathrm{wt} \% \mathrm{SN}$ and $0.5 \mathrm{wt} \%$ NaODFB+ $3 \mathrm{wt} \%$ $\mathrm{VC}+3 \mathrm{wt} \% \mathrm{SN}+0.2 \mathrm{wt} \% \mathrm{TMSPi}$ respectively. A clear evolution in exothermic heat was observed in moving from $2^{\text {nd }}$ charge to $3^{\text {rd }}$ charge, especially above $3.8 \mathrm{~V}$; however the evolutions are minimum in (c), (d) and (e) indicating faster stabilisation of positive electrode in these electrolytes. (The data were derived from same cells whose first charges were shown in supporting Figure S4, S5 and Figure 2.) 


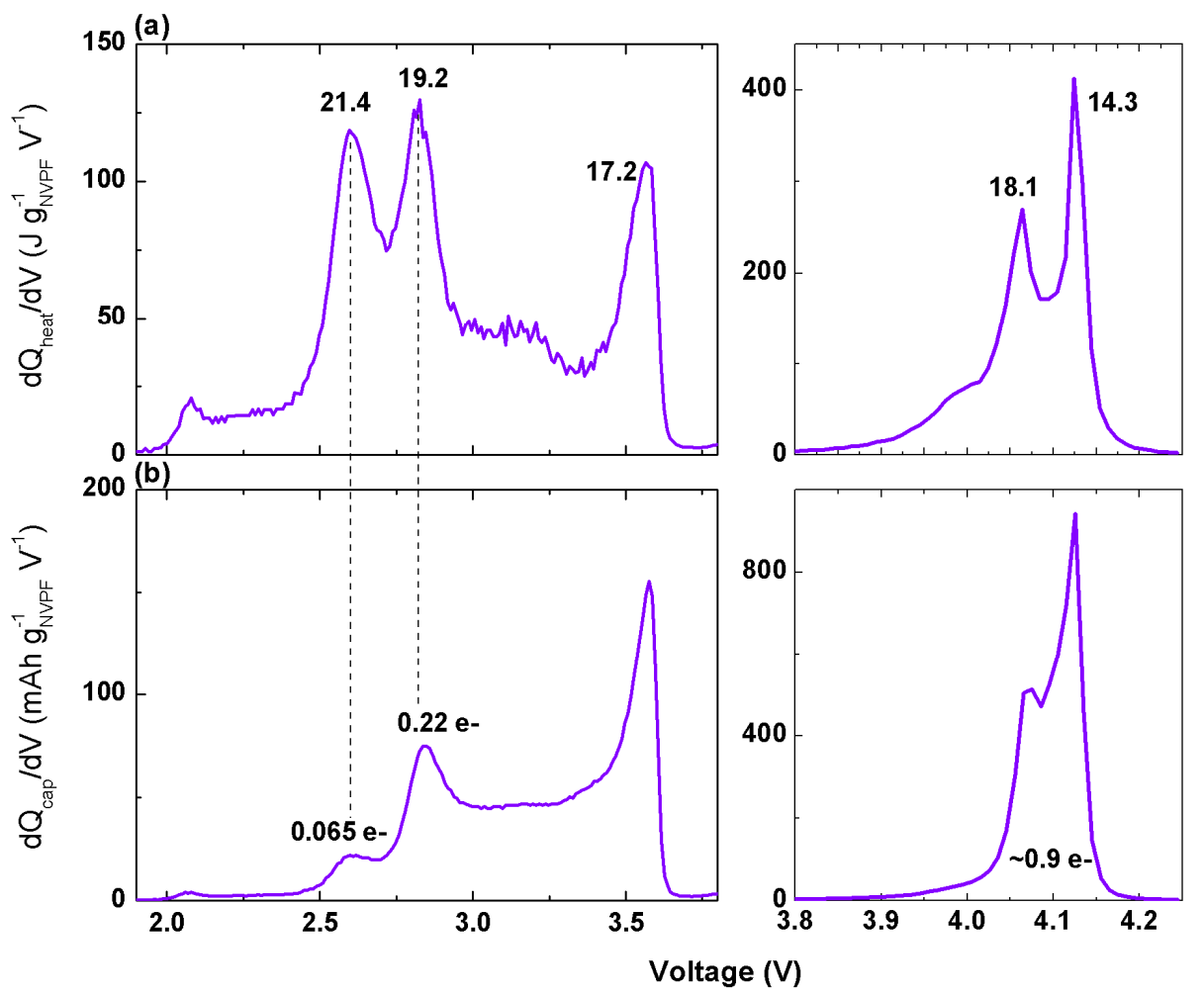

Figure S7. Comparison of derivative heat $\left(\mathrm{dQ}_{\text {heat }} / \mathrm{dV}\right)$ with derivative capacity $\left(\mathrm{dQ} \mathrm{Q}_{\mathrm{cap}} / \mathrm{dV}\right)$ as a function of potential (V) for the NVPF/HC cylindrical 18650 cells using $1 \mathrm{M} \mathrm{NaPF}_{6}$ in EC- PC- DMC (1: 1: 1 by volume) with additives $\mathrm{NaODFB}+\mathrm{VC}$. The cells were cycled at $55^{\circ} \mathrm{C}$ using $\mathrm{C} / 10$ rate. The total heats (in joules per gram of NVPF) for each exothermic peak were measured by integrating the total area under the peak and are mentioned in (a). Similarly, the corresponding electrons involved were measured from the capacity obtained in that voltage region and converting them to $\Delta \mathrm{Na}$, hence electrons (e ${ }^{-}$). The heat evolution peaks at $2.6 \mathrm{~V}$ and $2.8 \mathrm{~V}$ have almost similar area but the corresponding $\mathrm{e}^{-}$involved at $2.6 \mathrm{~V}$ are less than that at $2.8 \mathrm{~V}$, indicating the process at $2.6 \mathrm{~V}$ is highly exothermic chemical/ electrochemical reaction. (Related to Figure S2c) 


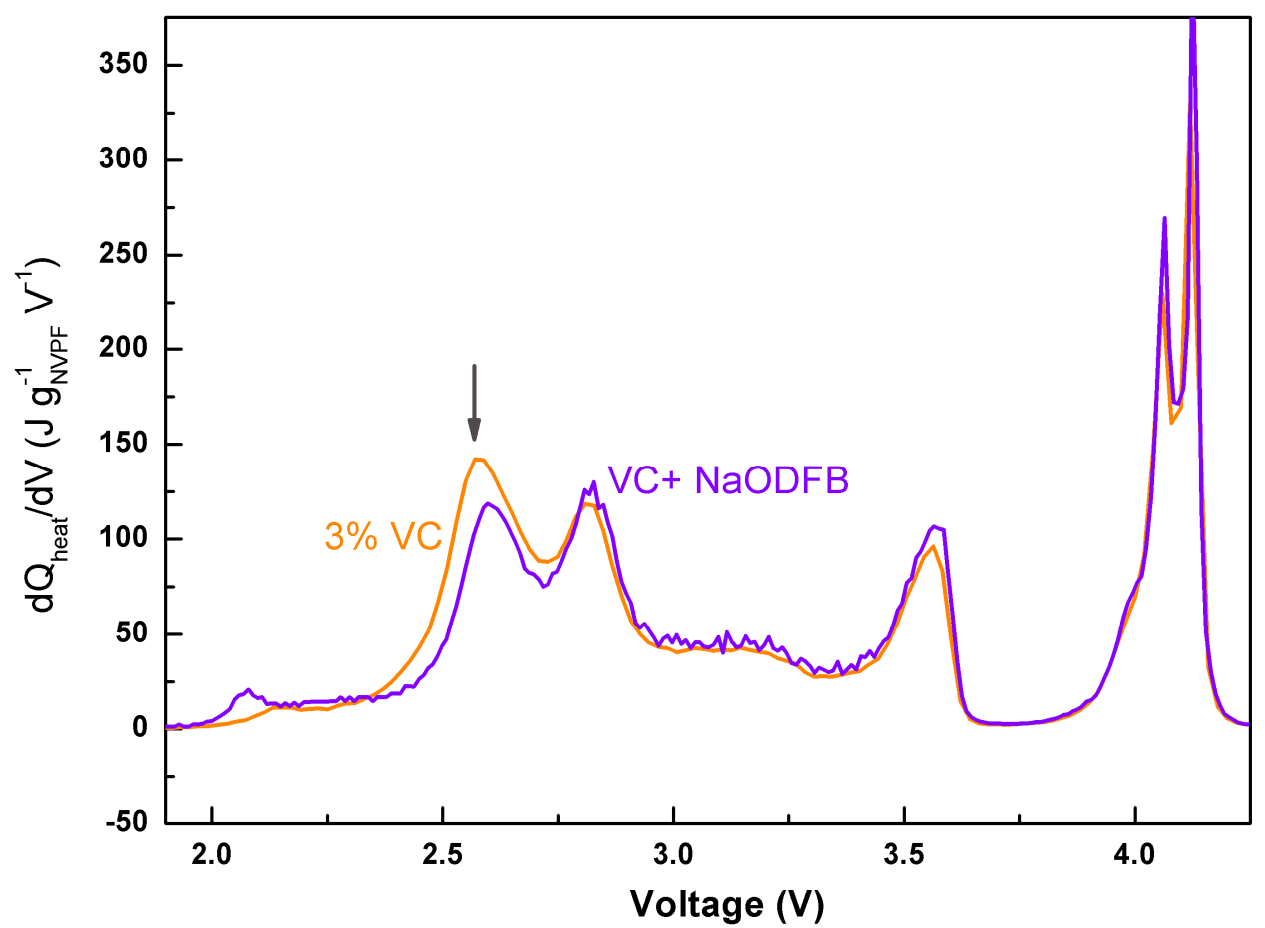

Figure S8. The heat derivatives $d Q_{\text {heat }} / \mathrm{dV}$ vs. V of NVPF/ HC cylindrical 18650 cells cycled at $55^{\circ} \mathrm{C}$. The data from two different electrolyte formulations were compared in which one electrolyte was $1 \mathrm{M} \mathrm{NaPF}_{6}$ in EC-PC-DMC (1:1: 1 by volume) with solely $3 \mathrm{wt} \% \mathrm{VC}$ as additive and the other one had $0.5 \mathrm{wt} \%$ $\mathrm{NaODFB}+3 \% \mathrm{VC}$. In short, both electrolytes differ only by presence or absence of NaODFB additive. Relatively lesser heat was observed at $2.6 \mathrm{~V}$ process when $\mathrm{VC}$ is used together with NaODFB indicating the possible suppression of VC reduction by the addition of NaODFB. (Related to Figure S2c) 


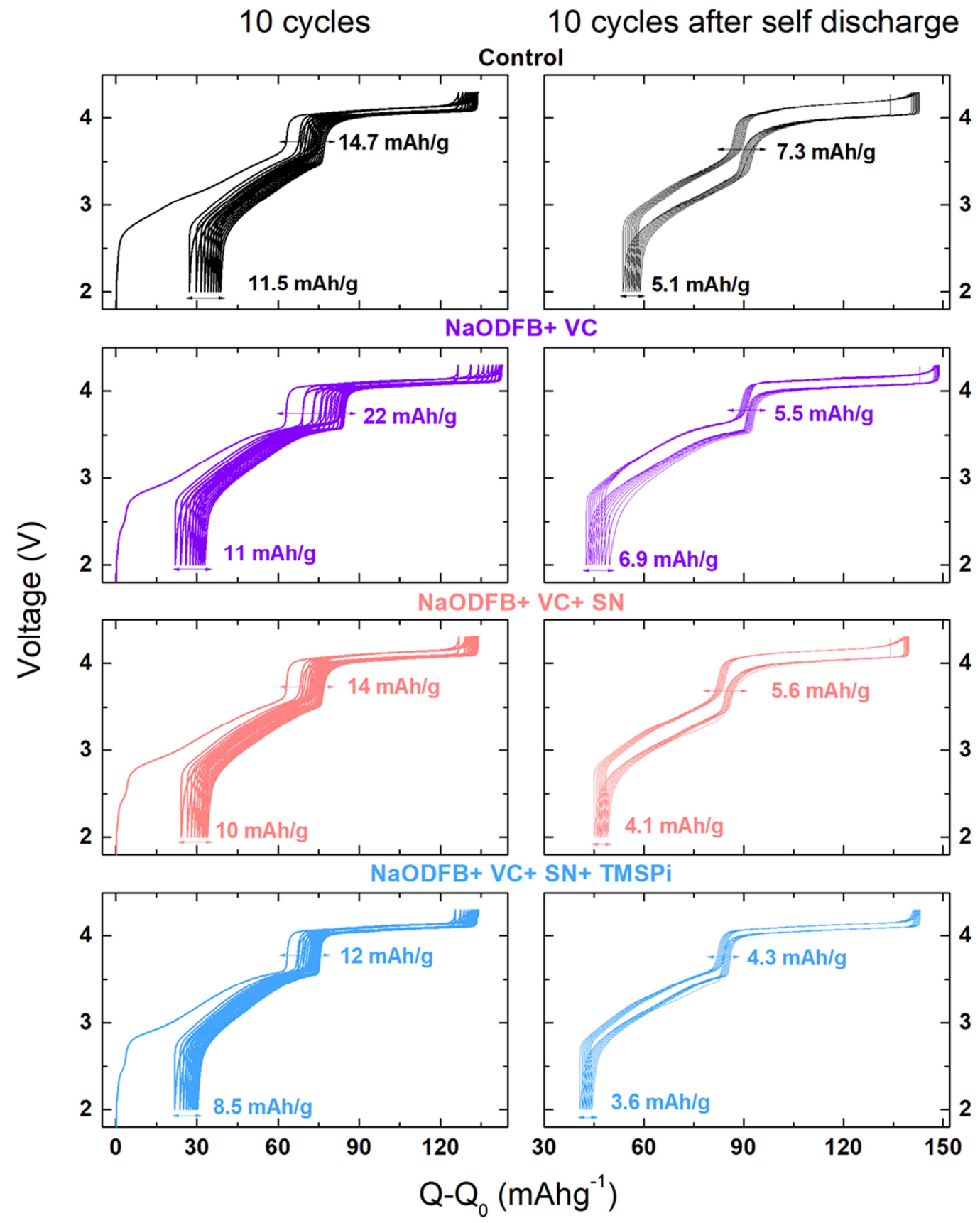

Figure S9. Voltage vs. capacity $\left(\mathrm{Q}-\mathrm{Q}_{0}\right)$ of NVPF/HC coin cells cycled with different electrolyte formulations at $55{ }^{\circ} \mathrm{C}$. The cells were cycled for 10 cycles at $\mathrm{C} / 5$ rate and allowed to rest during the $11^{\text {th }}$ charge at $4.3 \mathrm{~V}$ $(100 \%$ SOC) for 1 week. The cycling curves for the initial 10 cycles and the next 10 cycles after selfdischarge tests were cumulated in left and right. The consolidated parameters such as capacity loss and change in polarisation during self-discharge, capacity retention are reported in Figure 3. Capacity losses happening at end of discharge and at around $50 \%$ SOC are marked in the Figure. Feature at $50 \%$ SOC is the signature of NVPF and changes in that feature is directly correlated to the slippage of NVPF. The least capacity loss was observed with electrolyte containing 4 additives NaODFB+ VC+ SN+TMSPi. 

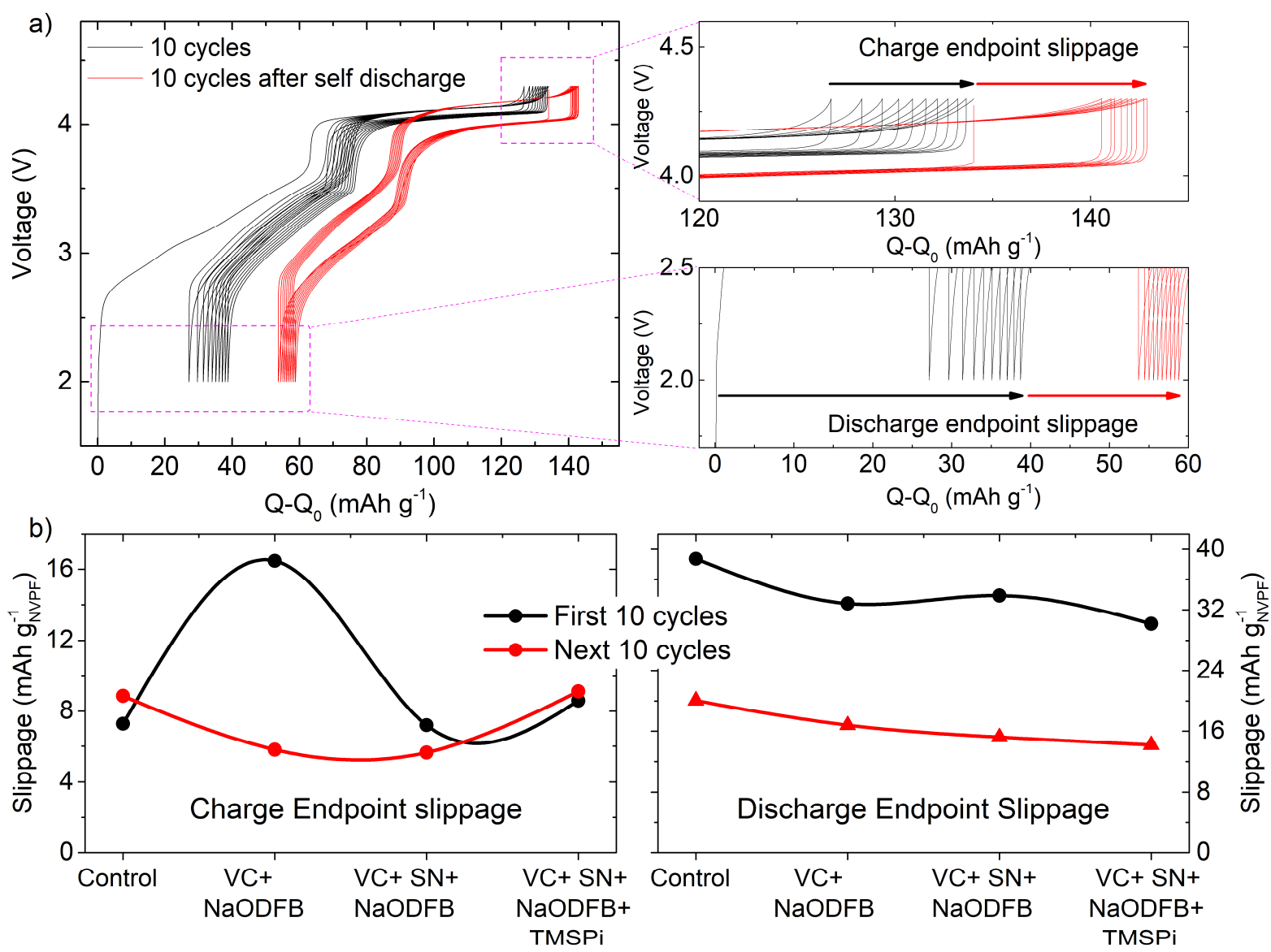

Figure S10. The end point slippage capacity in charge and discharge are measured as shown in Figure S10(a). The values for 10 cycles were calculated together to minimize the experimental error. The values thus calculated before and after self-discharge for various cells using different electrolyte formulations were consolidated in Figure S10(b). Highest end point slippage in charge is observed with electrolyte containing NaODFB+ VC specifying its poor oxidative stability. Such end point slippage is reduced with the addition of SN and TMSPi. Still, a small increase in both charge and discharge end point slippage capacity is observed with $\mathrm{NaODFB}+\mathrm{VC}+\mathrm{SN}+\mathrm{TMSPi}$ than that of the electrolyte without TMSPi (NaODFB+ VC+ SN). It could be related to the oxidation of TMSPi or its reduction product in the positive electrode. 

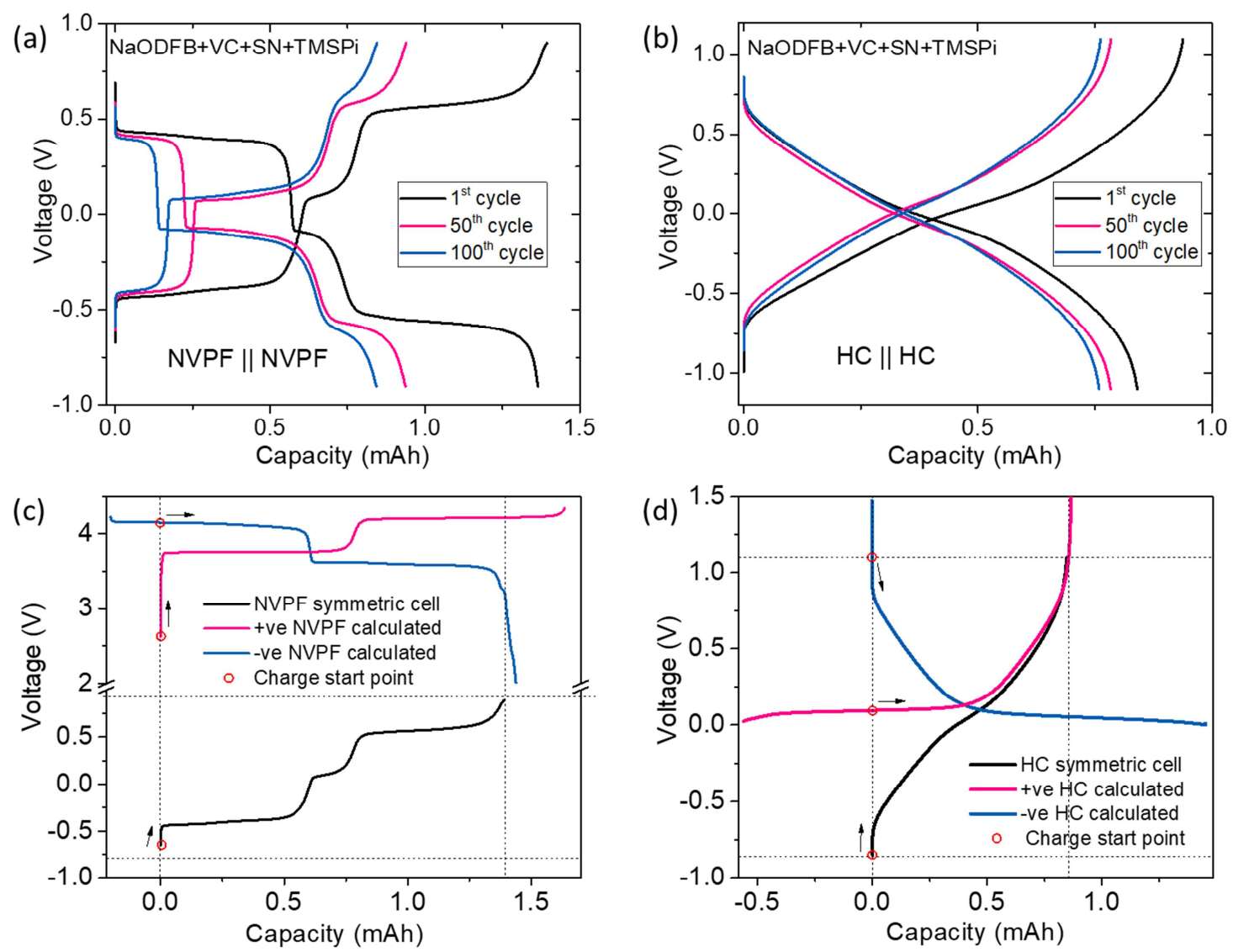

Figure S11. Galvanostatic curves for $1^{\text {st }}, 50^{\text {th }}$ and $100^{\text {th }}$ cycle of (a) NVPF and (b) HC symmetric cells with $\mathrm{NaODFB}+\mathrm{VC}+\mathrm{SN}+\mathrm{TMSPi}$ electrolyte and cycled at $\mathrm{C} / 5$ rate at room temperature. The observed three plateau profile, in contrast to two plateau profile for NVPF material is unanticipated. But, the $d V / d Q$ fitting performed using the software ${ }^{1}$ developed by Dahn et al., helped us to identify the individual electrode curves. The $1^{\text {st }}$ cycle charging curve is fitted using dV/dQ software and is presented for (c) NVPF and (d) $\mathrm{HC}$. In the fitted curves the red circles shows the starting point of the charge for symmetric cell and individual electrodes. With the knowledge of the $V(Q)$ profile of +ve and -ve NVPF it is much easier to visualize the shape of the symmetric cell curve since $V(Q)_{N V P F}$ symmetric cell $=V(Q)_{+v e ~ N V P F}-V(Q)_{\text {-ve NVPF. }}$. The same goes for $H C$ symmetric cells i.e. $V(Q)_{H C}$ symmetric cell $=V(Q)_{+v e} H C-V(Q)$-ve $H C$. These deconvoluted $V$ vs $Q$ curves for different cycles can provide the potential information about the reactions happening at the electrodes. (Related to Figure 5) 

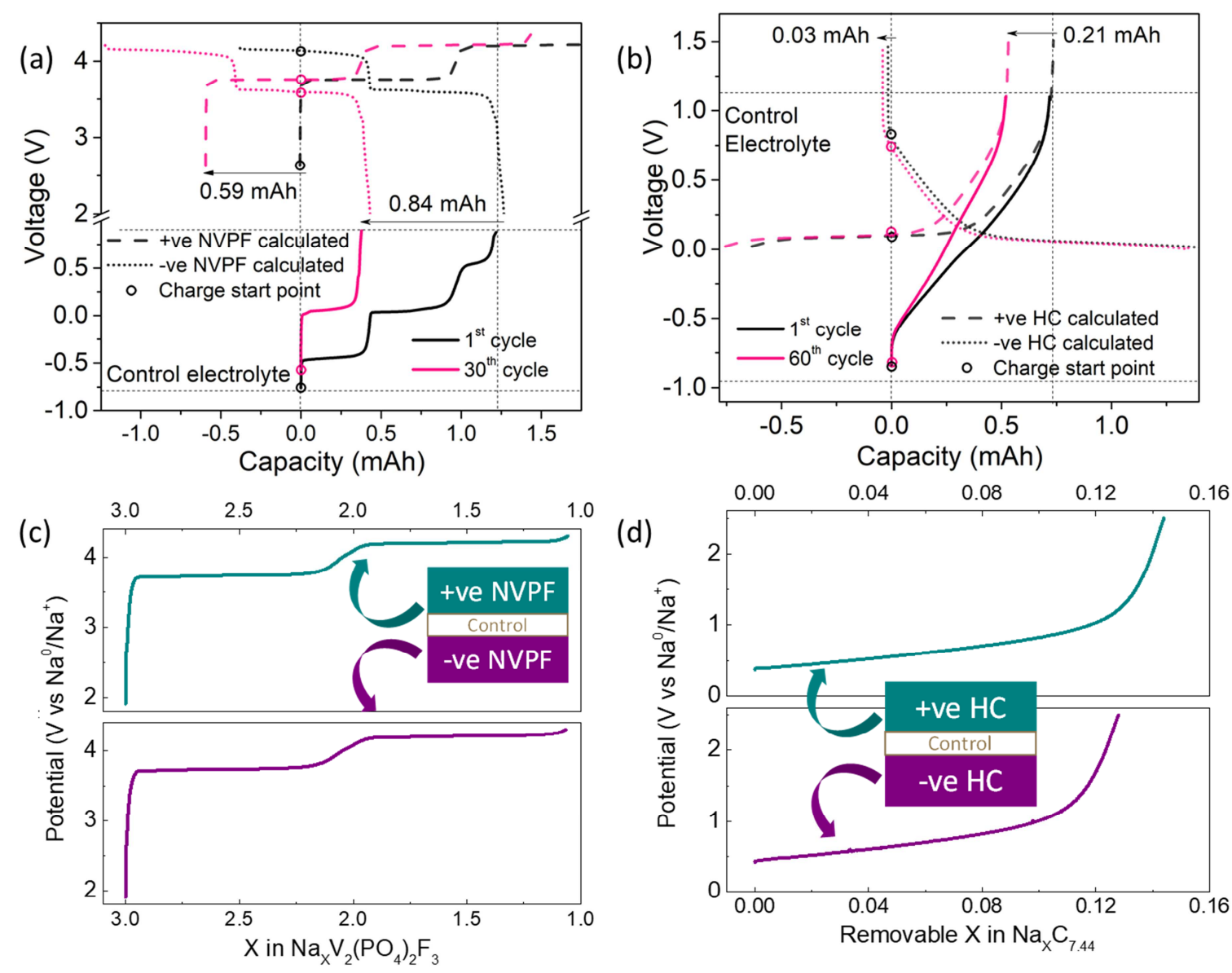

Figure S12. (a) The $1^{\text {st }}$ and $30^{\text {th }}$ cycle of NVPF symmetric cells with control electrolyte and the fitted $+v e$ NVPF (dahshed) and -ve NVPF (dotted) curves. Electrode slippage at -ve NVPF(0.84 mAh) and +ve NVPF(0.59 mAh) is indicated. After 100 cycles, NVPF symmetric cell was decrimped and +ve NVPF/Na and -ve NVPF/Na half cells were prepared and sodium was extrated from NVPF, (c) shows the half cell curves. To our surprise both the NVPF had almost 3 sodium.(b) The $1^{\text {st }}$ and $30^{\text {th }}$ cycle of HC symmetric cells with control electrolyte and the fitted +ve $\mathrm{HC}$ (dashed) and -ve $\mathrm{HC}$ (dotted) curves. In this case slippage of +ve HC $(0.21 \mathrm{mAh})$ is significantly higher than the -ve HC $(0.03 \mathrm{mAh})$. After 100 cycles, HC symmetric cell was decrimped and $+\mathrm{ve} \mathrm{HC} / \mathrm{Na}$ and $-\mathrm{ve} \mathrm{HC} / \mathrm{Na}$ half cells were prepared and sodium was extrated from $\mathrm{HC}$, (d) shows the half cell curves. Total $\mathrm{Na}^{+}$in the $\mathrm{HC}$ electrodes is 0.27 (where $\mathrm{x}=1$ corrosponds to $300 \mathrm{mAh} / \mathrm{g}$ of capacity for $\mathrm{Na}_{x} \mathrm{C}_{7.44}$ ). 


\section{Supporting Notes.}

Note S1. To make symmetric cells, both the NVPF and HC electrodes are sodiated or desodiated as per the requirement (explained in Experimental Procedure), in NVPF/ HC full cells using the electrolyte formulation under study. The cells are decrimped and the electrodes recovered and used without washing the formed SEI/CEI. The desodiated NVPF (-ve NVPF) in Figure S11c doesn't start with composition $\mathrm{Na}_{1} \mathrm{~V}_{2}\left(\mathrm{PO}_{4}\right)_{2} \mathrm{~F}_{3}$, but with slightly more sodium. Similarly, Sodiated $\mathrm{HC}$ starts with the less sodium than it was sodiated (Figure S12d). After many experimental trials, it was observed that it was impossible to completely avoid this behaviour. The possible reason of this behaviour could be the process of decrimping the cell and assembling it again with fresh electrolyte. Since sodiated HC and desodiated NVPF materials are highly reactive they will try to lose and gain sodium, respectively.

Note S2. In Figure S12a the slippage at -ve electrode is $0.84 \mathrm{mAh}$ which is more than the slippage at +ve electrode, $0.59 \mathrm{mAh}$. Refereing to the starting point of fitted curves, -ve NVPF and +ve NVPF slippage is attributed to the gain and loss of $\mathrm{Na}^{+}$respectively, considering there is no mass loss. The same behaviour of -ve NMC slippage more than +ve NMC slippage can be observed in NMC symmetric cells ${ }^{2}$. This indicates that there is increase in the total sodium content in the electrode.To confirm this, after 100 cycles, NVPF symmetric cell was decrimped and $+\mathrm{ve}$ NVPF/Na and $-\mathrm{ve} \mathrm{NVPF} / \mathrm{Na}$ half cells were prepared and sodium was extrated from NVPF(shown in Figure S12c), to our surprise both the NVPF had almost 3 sodium. This indicates gain of sodium from electrolyte, which happens with simultaneous oxidation of electrolyte. Since both NVPF electrodes are at high voltage, the possibility of electrolyte reduction is negligible, hence the only dominant mechanism of degradation is electrolyte oxidation. This eliminates the cross talk caused by the reaction of reduced and oxidized species on cathode and anode electrode respectively. From the slippage of the individual electrode curves, it is established that the additive which decreases the extent of electrolyte oxidation decreases the slippage in the electrode and hence stabilizes symmetric cell capacity. (related to Figure S12a, S12c and Figure 5)

Note S3. In Figure $12 b)$ the slippage of +ve HC $(0.21 \mathrm{mAh})$ is significantly higher than the -ve HC $(0.03$ $\mathrm{mAh}$ ). Refering to the starting point of fitted curves, it is evident that slippage at +ve HC and -ve HC stems from $\mathrm{Na}^{+}$loss and $\mathrm{Na}^{+}$gain respectively,considering there is no mass loss. To confirm this, after 100 cycles, $\mathrm{HC}$ symmetric cell was decrimped and $+v e \mathrm{HC} / \mathrm{Na}$ and $-\mathrm{ve} \mathrm{HC} / \mathrm{Na}$ half cells were prepared and sodium was extrated from $\mathrm{HC}$ (shown in Figure $\mathrm{S} 12 \mathrm{~d}$ ). Total extracted $\mathrm{Na}^{+}$in the $\mathrm{HC}$ electrodes is 0.27 (where $\mathrm{x}=1$ corrosponds to $300 \mathrm{mAh} / \mathrm{g}$ of capacity for $\mathrm{Na}_{x} \mathrm{C}_{7.44}$ ). Initial $\mathrm{Na}^{+}$amount after sodiation of $\mathrm{HC}$ for symmetric cells was 0.63 (calculated from the capacity obtained in the first cycle of symmetric cell). This indicates loss of sodium to electrolyte with simultaneous electrolyte reduction and SEI growth. Since both $\mathrm{HC}$ electrodes are at low voltage, so the possibility of electrolyte oxidation is negligible. (related to Figure S12b, S12d and Figure 5)

\section{References.}

1. Dahn HM, Smith AJ, Burns JC, Stevens DA, Dahn JR. User-Friendly Differential Voltage Analysis Freeware for the Analysis of Degradation Mechanisms in Li-lon Batteries. J Electrochem Soc. 2012 Aug 14;159(9):A1405.

2. Shen C, Xiong D, Ellis LD, Gering KL, Huang L, Dahn JR. Using the Charge-Discharge Cycling of Positive Electrode Symmetric Cells to Find Electrolyte/Electrode Combinations with Minimum Reactivity. J Electrochem Soc. 2017 Nov 2;164(13):A3349. 